\title{
When does eruption run-up begin? Multidisciplinary insight from the 1999 eruption of Shishaldin volcano
}

\author{
Daniel J. Rasmussen ${ }^{\mathrm{a}, *}$, Terry A. Plank ${ }^{\mathrm{a}}$, Diana C. Roman ${ }^{\mathrm{b}}$, John A. Power ${ }^{\mathrm{c}}$, \\ Robert J. Bodnar ${ }^{\mathrm{d}}$, Erik H. Hauri ${ }^{\mathrm{b}}$ \\ a Lamont-Doherty Earth Observatory, Columbia University, 61 Route 9W, PO Box 1000, Palisades, NY, 10964, USA \\ b Department of Terrestrial Magnetism, Carnegie Institution for Science, 5241 Broad Branch Road, N.W., Washington, D.C., 20015, USA \\ c Alaska Volcano Observatory, US Geological Survey, Volcano Science Center, 4200 University Dr., Anchorage, AK, 99508, USA \\ d Department of Geosciences, Virginia Tech, 4044 Derring Hall, 926 West Campus Drive, Virginia Tech, Blacksburg, VA, 24061, USA
}

\section{A R T I C L E I N F O}

\section{Article history:}

Received 15 September 2017

Received in revised form 20 December 2017

Accepted 2 January 2018

Available online 19 January 2018

Editor: T.A. Mather

Keywords:
run-up
precursor
eruption
diffusion chronometry
magma mixing
shear-wave splitting

\begin{abstract}
A B S T R A C T
During the run-up to eruption, volcanoes often show geophysically detectable signs of unrest. However, there are long-standing challenges in interpreting the signals and evaluating the likelihood of eruption, especially during the early stages of volcanic unrest. Considerable insight can be gained from combined geochemical and geophysical studies. Here we take such an approach to better understand the beginning of eruption run-up, viewed through the lens of the 1999 sub-Plinian basaltic eruption of Shishaldin volcano, Alaska. The eruption is of interest due to its lack of observed deformation and its apparent long run-up time (9 months), following a deep long-period earthquake swarm. We evaluate the nature and timing of recharge by examining the composition of 138 olivine macrocrysts and 53 olivine-hosted melt inclusions and through shear-wave splitting analysis of regional earthquakes. Magma mixing is recorded in three crystal populations: a dominant population of evolved olivines $\left(\mathrm{Fo}_{60}-69\right)$ that are mostly reversely zoned, an intermediate population $\left(\mathrm{Fo}_{69-76}\right)$ with mixed zonation, and a small population of normally zoned more primitive olivines ( $\mathrm{Fo}_{76}-80$ ). Mixing-to-eruption timescales are obtained through modeling of $\mathrm{Fe}-\mathrm{Mg}$ interdiffusion in 78 olivines. The large number of resultant timescales provides a thorough record of mixing, demonstrating at least three mixing events: a minor event $\sim 11$ months prior to eruption, overlapping within uncertainty with the onset of deep long-period seismicity; a major event $\sim 50$ days before eruption, coincident with a large (M5.2) shallow earthquake; and a final event about a week prior to eruption. Shear-wave splitting analysis shows a change in the orientation of the local stress field about a month after the deep long-period swarm and around the time of the M5.2 event. Earthquake depths and vapor saturation pressures of Raman-reconstructed melt inclusions indicate that the recharge magma originated from depths of at least $20 \mathrm{~km}$, and that mixing with a shallow magma or olivine cumulates occurred in or just below the edifice $(<3 \mathrm{~km}$ depth). Deformation was likely outside the spatial and temporal resolution of the satellite measurements. Prior to eruption magma was stored over a large range of depths $(\sim 0-2.5 \mathrm{~km}$ below the summit), suggesting a shallow, vertical reservoir that could provide another explanation for the lack of detectable deformation. The earliest sign of unrest (deep long-period seismicity) coincides temporally with magmatic activity (magma mixing and a change in the local stress state), possibly indicating the beginning of eruption run-up. The more immediate run-up began with the major recharge event $\sim 50$ days prior to eruption, after which the signs of unrest became continuous. This timescale is long compared to the seismic run-up to other basaltic eruptions (typically hours to days). Other volcanoes classified as open-system, based on their lack of precursory deformation, also tend to have relatively long run-up durations, which may be related to the time required to fill the shallow reservoir with magmas sourced from greater depth.
\end{abstract}

(C) 2018 Elsevier B.V. All rights reserved.

\footnotetext{
* Corresponding author.

E-mail addresses: danielr@Ideo.columbia.edu (D.J. Rasmussen), tplank@ldeo.columbia.edu (T.A. Plank), droman@carnegiescience.edu (D.C. Roman), jpower@usgs.gov (J.A. Power), rjb@vt.edu (R.J. Bodnar), ehauri@carnegiescience.edu
} (E.H. Hauri).

\section{Introduction}

Unraveling the sequence and duration of magmatic events preceding volcanic eruptions is central to understanding volcanoes and the hazards they pose. Real-time volcano monitoring during 
unrest provides unparalleled insight into stirrings deep within a magmatic system (Sparks, 2003). However, translation of the signals into magmatic processes is challenging, and only a handful of eruptions are well monitored. Petrology offers powerful tools to study eruption run-up that benefit from direct response to magmatic forcings and applicability to most eruptions. Diffusion chronometers (or crystal clocks) give insight into crystal residence times (Cooper and Kent, 2014), mixing-to-eruption timescales (Costa and Chakraborty, 2004), magma ascent rates (Lloyd et al., 2013), and cooling rates (Newcombe et al., 2014). Solubility barometers indicate the depths of magmatic processes (Spillieart et al., 2006). Further insight into the timing of magmatic events can be gained by applying modern seismological techniques to older datasets to glean new information (e.g., stress field analysis; Roman and Gardine, 2013). Developing these tools, and tying them to monitoring data, will help identify eruption triggers and understand the significance of real-time observations during unrest (e.g., Kahl et al., 2011; Rae et al., 2016).

An important goal for combined geochemical and geophysical research is understanding the earliest signals of volcanic unrest. In many cases, magma recharge and mixing are thought to initiate eruptions (Sparks et al., 1977). Geodetic methods can give insight into the first signs of recharge (Lu and Dzurisin, 2014). However, many volcanoes lack measurable deformation signals (open-system volcanoes) for reasons that are not well understood (Ebmeier et al., 2013). Deep long-period earthquakes (DLPs) may result from magma movement deep within the crust (Power et al., 2004), thereby providing another potential early sign of recharge. Interestingly, there have only been a few cases where DLPs have been identified as part of a precursory sequence (e.g., Power et al., 2013, 2004; White, 1996). To better understand the duration of eruption run-up, it is necessary to combine information on magma recharge with extremely subtle indicators of stress or deformation (e.g., shear-wave splitting) and the occurrence of DLPs prior to eruptions.

As a case study, we examine the 1999 sub-Plinian basaltic eruption of Shishaldin volcano, Alaska, one of the few examples where DLPs are suggested to be the earliest precursor to eruption (Power et al., 2004). While most basaltic eruptions have run-up durations on the order of hours to days (Passarelli and Brodsky, 2012), the earliest detected DLP swarm at Shishaldin occurred $\sim 9$ months prior to eruption, implying an abnormally long run-up. Interferometric synthetic aperture radar (InSAR) images that span the DLP swarm lack indication of inflation (Moran et al., 2006), which may be related to spatiotemporal limitations of the old dataset and/or the general lack of observed inter- and intra-eruptive deformation at Shishaldin over the past 20 yrs (Lu and Dzurisin, 2014; Moran et al., 2006). We focus on this eruption to determine (1) when eruption run-up began and (2) why there was no readily InSAR-detectable geodetic signal. Both require a detailed understanding of the location of magmas in space and time prior to the eruption. A comprehensive set of real-time observations chronicle the run-up and ultimate VEI 3 eruption (Nye et al., 2002). We build on these observations using geochemical and geophysical tools. Magma depths are examined by employing solubility barometry, using measured and reconstructed volatile contents of melt inclusions. The timing of magma recharge is investigated using compositional gradients in olivine for diffusion chronometry and seismic shear-wave splitting patterns as indicators of stress. Finally, we consider Shishaldin in the context of other open-system volcanoes and compare our results with seismically defined run-up timescales from the literature (Passarelli and Brodsky, 2012).

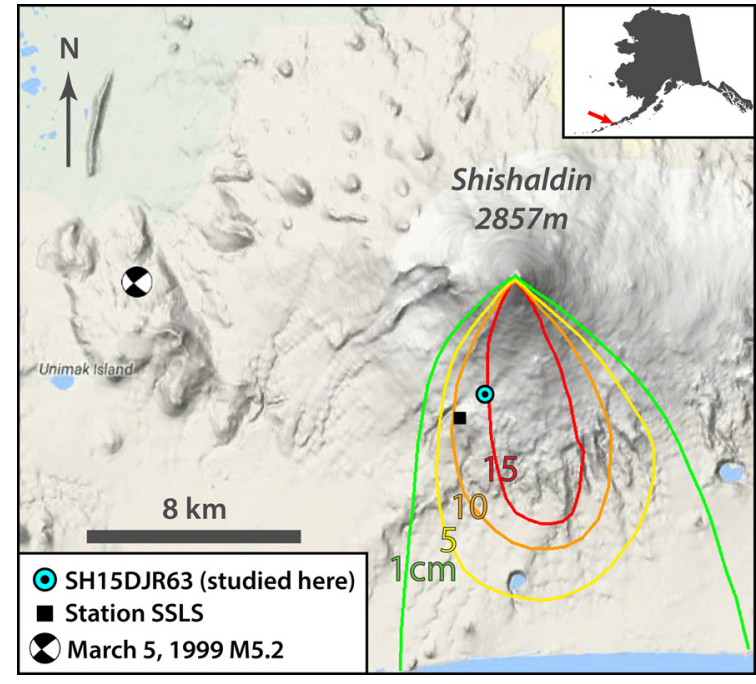

Fig. 1. Thickness of deposits from the 1999 eruption of Shishaldin volcano (after Stelling et al., 2002). The total volume of erupted products is $4.3 \times 10^{7} \mathrm{~m}^{3}$ (or $1.4 \times 10^{7} \mathrm{~m}^{3}$ dense rock equivalent; Stelling et al., 2002). Sample SH15DJR63 (IGSN: TAP00005C), located at N54.71895 W163.98648 (WGS84), was collected in 2015 and is studied here. SSLS is a three-component short-period seismic station operated by the Alaska Volcano Observatory. Focal mechanism for the M5.2 from Moran et al. (2002). Base map from Google Maps.

\section{Eruption timeline}

Activity precursory to the 1999 eruption of Shishaldin likely started in July 1998 with the occurrence of a swarm of long period (LP) earthquakes, spanning depths of $>15$ to $\sim 0 \mathrm{~km}$ below sea level (BSL) (Moran et al., 2002). A second, minor swarm occurred in September-October (Moran et al., 2002). Little activity followed until February 1999, when low-level seismic tremor initiated (Thompson et al., 2002). On February 9, a thermal anomaly appeared in the summit crater (Dehn et al., 2002). Around the same time, vigorous steam plumes were observed, and low-level tremor became continuous (Nye et al., 2002). Precursory activity reached a crescendo on March 4 with a shallow $(\sim 0 \mathrm{~km}$ BSL), strike-slip M5.2 tectonic earthquake located $16 \mathrm{~km}$ west of Shishaldin (Moran et al., 2002). Aftershocks followed, causing a significant increase in the rate of earthquakes (Thompson et al., 2002). After minor Strombolian activity that began as early as late March (Dehn et al., 2002), a sub-Plinian, VEI 3 event occurred on April 19. In only $\sim 80$ mins, $\sim 4.3 \times 10^{7} \mathrm{~m}^{3}$ of basaltic scoria (or $1.4 \times 10^{7} \mathrm{~km}^{3}$ dense rock equivalent) was ejected in two short bursts, with plumes reaching heights of $\sim 9$ and $\sim 16 \mathrm{~km}$ (Nye et al., 2002). After the initial sub-Plinian explosion, the eruption shifted to vigorous, pulsating Strombolian bursts for $\sim 2.5 \mathrm{hrs}$, and similar activity continued sporadically into May (Nye et al., 2002).

\section{Sample description}

We study a tephra fall deposit (SH15DJR63; IGSN: TAP00005C; Fig. 1) associated with the sub-Plinian phase of the eruption, the only phase to produce significant deposits (Stelling et al., 2002). The deposit was thick $(>1 \mathrm{~m})$ and continuous in the area sampled. Clast sizes range from fine ash to coarse lapilli, with rare blocks and bombs. The sample is basaltic $\left(50 \mathrm{wt} . \% \mathrm{SiO}_{2}\right)$ in its whole rock and matrix glass composition (Tables C.3, C.4). Plagioclase feldspar is moderately abundant ( $\sim 20 \%$ modal abundance) and lesser, subequal portions of olivine and clinopyroxene are present ( $\sim 3 \%$ each). Loose olivine $(0.5-1 \mathrm{~mm})$ from ash size fraction is studied. It is typically subhedral-euhedral with occasional dissolution textures. Olivine-hosted melt inclusions occur infrequently and vary in size (40-180 $\mu \mathrm{m}$, average $70 \mu \mathrm{m}$, diameter). Most lack co-entrapped 
crystal inclusions ( $>60 \%$ ) or vapor bubbles ( $>70 \%$ ). Vapor bubbles occupy 1-8 vol.\% (3 vol.\% average). Melt inclusions studied here were examined individually, and all are fully enclosed, glassy, and lack visual signs of decrepitation (e.g., wisps of glass in the host olivine, cracks, oversized bubbles).

\section{Geochemical methods}

Detailed analytical methods are given in Appendix B, and data are reported in Appendix C.

\subsection{Analyses of olivine compositional profiles}

A survey of 162 olivines was conducted by laser ablation inductively coupled plasma mass spectrometry (LA ICP-MS) using a VG PQ Excell mass spectrometer interfaced with a NewWave $193 \mathrm{~nm}$ ArF Eximer laser at Lamont-Doherty Earth Observatory. Of the 162 surveyed olivines, 85 were selected for further analysis based on the following criteria: presence of adhering matrix glass, minimal fractures, relatively simple zonation patterns, and cuts appearing to be on-center per criteria in Shea et al. (2015a). For the 85 selected olivines and the 53 olivine hosts of melt inclusions, we obtained backscattered electron (BSE) images using a Zeiss EVO60 variable pressure scanning electron microscope at the American Museum of Natural History (AMNH). For zoned crystals (84 olivines, including 17 inclusion hosts; Appendix D), we also collected electron backscatter detection (EBSD) patterns to determine crystallographic orientation. Quantitative measurements of olivine compositions were obtained using a Cameca SX-100 electron microprobe (EMP) at the AMNH. BSE grayscale values were fitted to olivine forsterite determined by EMP using a linear regression (in most cases, $\mathrm{R}^{2}>0.9$ ).

\subsection{Analyses of melt inclusions and matrix glasses}

We examined 53 olivine-hosted melt inclusions, 25 containing vapor bubbles (photomicrographs in Appendix E). $\mathrm{CO}_{2}$ density in the bubbles was measured by Raman spectroscopy using a JY Horiba LabRam HR $(800 \mathrm{~mm})$ spectrometer connected to a $514 \mathrm{~nm}$ Laser Physics laser at Virginia Tech, following Lamadrid et al. (2017). $\mathrm{H}_{2} \mathrm{O}$ and $\mathrm{CO}_{2}$ contents in 49 inclusions and 12 matrix glasses were measured using a Thermo-Nicolet Nexus 670 FTIR spectrometer coupled with a Continuum IR microscope at the $\mathrm{AMNH}$. Major elements and volatiles $(\mathrm{S}, \mathrm{Cl})$ were measured in inclusions and matrix glasses on the AMNH EMP.

\subsection{Accounting for post-entrapment changes to melt inclusion compositions}

Post-entrapment crystallization (or melting), termed PEC (or PEM), of olivine along the melt inclusion-olivine interface is common. The process occurs when the olivine-melt equilibrium shifts after inclusion entrapment, primarily due to cooling or heating. We tested for PEC/PEM by evaluating the equilibrium host Fo. To calculate the equilibrium host composition, the Fe speciation and the $\mathrm{Fe}-\mathrm{Mg}$ olivine-melt partitioning $\left(\mathrm{K}_{\mathrm{D}}^{\mathrm{Fe}-\mathrm{Mg}}\right)$ must be known. To obtain oxygen fugacity, the olivine-melt $\mathrm{V}$ partitioning oxybarometer of Canil (2002) was applied to matrix-glass-olivine pairs analyzed by LA ICP-MS. Calculated values of NNO are -1 to +1 that average to NNO $+0 \pm 0.5$ (or \pm 0.2 using the standard error of the mean) (Fig. A.1a). Fe speciation was determined using Eq. 6 of Kress and Carmichael (1991), which yields an average $\mathrm{Fe}^{3+} / \mathrm{Fe}^{\mathrm{T}}$ of $0.19 \pm 0.03$ (Fig. A.1b). We followed Toplis (2005) to calculate $\mathrm{K}_{\mathrm{D}}^{\mathrm{Fe}-\mathrm{Mg}}$ (avg. 0.32). In many cases (22 of 53), inclusions were in equilibrium with a host composition that is within $1 \mathrm{~mol} \%$ of the measured host Fo (Fig. A.2), reflecting minor PEC/PEM. We corrected for these processes by incremental addition (or in the cases of PEM, subtraction) of olivine until equilibrium is satisfied. Calculations were performed using a Monte Carlo approach, conducting 200 trials for each inclusion in which inclusion and host compositions and Fe speciation were varied over their uncertainties. Most (83\%) inclusions without vapor bubbles experienced PEM (avg. 1.5 wt.\% olivine), whereas bubble-bearing inclusions typically (58\%) underwent PEC (avg. 1.5 wt.\%).

Vapor bubbles can form in melt inclusions during cooling and crystallization, diffusive $\mathrm{H}^{+}$loss, and depressurization during ascent. The bubbles typically contain $\mathrm{CO}_{2}$ (Hartley et al., 2014; Moore et al., 2015) and possibly other volatile species (Esposito et al., 2016). We accounted for vapor bubble formation by adding $\mathrm{CO}_{2}$ in the bubble back into the inclusion following the methods of Moore et al. (2015). The density of $\mathrm{CO}_{2}$ in each bubble was calculated using the Raman-measured Fermi diad splitting and the calibration of Lamadrid et al. (2017). Our results suggest $97-\sim 100 \%$ of the originally entrapped $\mathrm{CO}_{2}$ was lost to the bubble.

\section{Olivine and melt inclusion populations}

\subsection{Olivine populations}

Olivines exhibit significant chemical variability, having an overall range of $\mathrm{Fo}_{53-80}, 0.05-0.36$ wt.\% $\mathrm{CaO}, 0.29-0.77$ wt.\% $\mathrm{MnO}$, and 25-566 ppm Ni. Olivine core compositions form one dominant and two lesser modes, and rims plot between the high- and low-Fo core modes (Fig. 2). The zonation patterns can be binned into four types: nominally unzoned, predominantly normally zoned (i.e., Fo decreases toward rim; Fig. 3a), predominantly reversely zoned (i.e., Fo increases toward rim; Figs. 3b, c), and irregular (not evaluated). In the 85 evaluated olivines, three distinct populations are delineated by olivine core compositions and zonation patterns (Fig. 2). Population 1 consists of the most evolved olivines (71 crystals with Fo58-69) that are mostly reversely zoned (83\%); fewer have no zonation (11\%) or normal zonation (6\%). Population 2 Fo $_{69-76}$ olivines have mixed zonation. Of the 11 crystals, $64 \%$ are reversely zoned and 36\% are normally zoned. Population 3 is comprised of the most primitive olivines (Fo76-80). All 3 are normally zoned. Steep, narrow $(<5 \mu \mathrm{m})$ zonation bands occur in 9 of the 85 evaluated crystals (e.g., Fig. $3 \mathrm{~b}$ ), which we consider to be the product of late stage growth or diffusion and do not consider in classifying zonation patterns or diffusion modeling.

\subsection{Melt inclusion and host olivine populations}

Melt inclusion host compositions, which are used for inclusion classification, follow the olivine populations described above (Fig. 2). Three populations are also reflected in inclusion major element, S, and $\mathrm{CO}_{2}$ compositions (Figs. 4, A.3, A.5). Most hosts are reversely zoned (57\%), and fewer lack zonation (23\%) or are normally zoned (20\%). All but 3 inclusions are in the unzoned core. Inclusion major element compositions are largely basaltic (2.8-5.7 wt.\% MgO, 46.4-53.3 wt.\% $\mathrm{SiO}_{2}$; Fig. A.3). Compositions diverge from the bulk rock array of Shishaldin toward elevated $\mathrm{FeO}_{\mathrm{T}}$ and lower $\mathrm{Al}_{2} \mathrm{O}_{3}$, which we ascribe to shallow plagioclase crystallization based on compositional similarity between population 1 inclusions and the matrix glass (Figs. A.3a, c). Population 3 (a single inclusion) plots with the bulk rock compositions, and population 2 is intermediate (Fig. A.3). In general, population 1 are the most degassed in volatiles, population 3 the least, and population 2 is intermediate (Figs. 4, A.4, A.5). $\mathrm{H}_{2} \mathrm{O}\left(0.1-2.5\right.$ wt.\%) and $\mathrm{CO}_{2}(\sim 0-2630 \mathrm{ppm})$ do not follow an equilibrium degassing path. Inclusions with high $\mathrm{H}_{2} \mathrm{O}$ and negligible $\mathrm{CO}_{2}$ concentrations indicate degassing occurred in a relatively open system (i.e., open-system degassing curve; Figs. 4, 


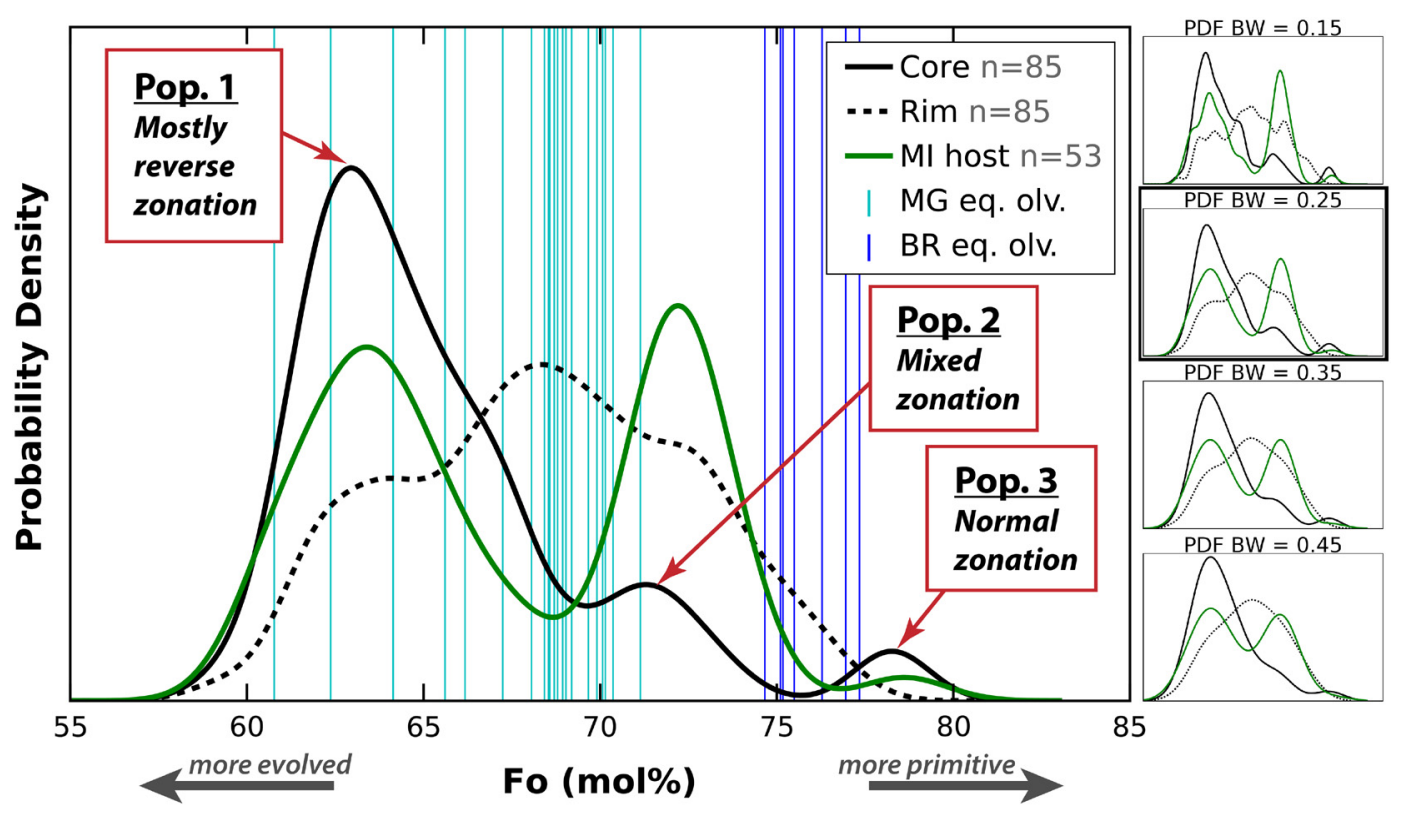

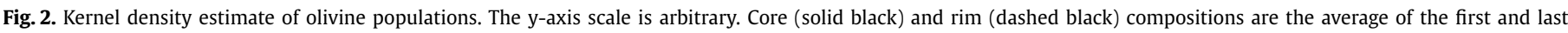

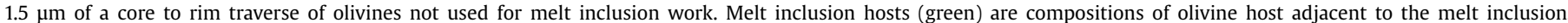

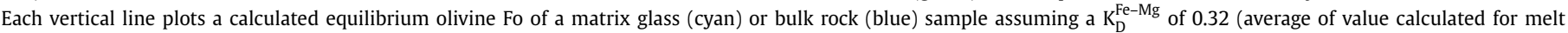

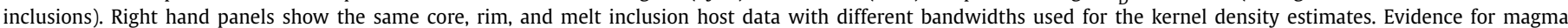

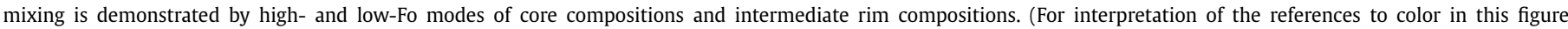
legend, the reader is referred to the web version of this article.)

A.6). Deviation from the open-system path is likely due to diffusive loss of $\mathrm{H}^{+}$, which is supported by the lack of a systematic relationship between $\mathrm{H}_{2} \mathrm{O}$ and $\mathrm{K}_{2} \mathrm{O}$ (Fig. A.5a) (Lloyd et al., 2013). Conversely, S correlates negatively with $\mathrm{K}_{2} \mathrm{O}$ (Fig. A.5c), consistent with crystallization driven by decompression and degassing.

\subsection{Evidence for magma mixing}

Olivine composition and zonation provide strong evidence for mixing. End-member scenarios are (1) mixing between less- and more-evolved magmas and (2) mixing between an intermediate magma and pre-existing olivine. In the first case, low-Fo (Population 1) and high-Fo (Population 3) olivine populations may reflect the end-member magmas, and the mixing reservoir is represented by intermediate rim compositions and population 2 crystals that have intermediate compositions and mixed zonation patterns (Fig. 2). Similar patterns in olivine compositions have been used to infer mixing at Mt. Etna (Kahl et al., 2011) and many other volcanoes (e.g., Killauea; Rae et al., 2016). Alternatively, crystal populations and zonation profiles could represent cumulate entrainment. In this case, a magma, represented by population 2 crystals, would have picked up two populations of pre-existing olivine (populations 1 and 3), drawing olivine compositions towards that of the intermediate magma. The thermal histories of melt inclusions corroborate both scenarios. Eruption temperatures are generally greater than entrapment temperatures for more inclusions in population 1, and vice versa in population 3 (Fig. A.7). Both cases, collectively referred to as magma mixing, have similar implications for the timing of recharge and will be explored together.

\section{Geochemical modeling}

\subsection{Modeling mixing-to-eruption time with Fe-Mg interdiffusion}

Upon magma mixing, melt-crystal equilibrium is shifted. Crystals respond by some combination of crystal growth, dissolution, and diffusion (Streck, 2008). The process of diffusive equilibration is often incomplete for certain elements at the time of eruption, leaving a chemical gradient frozen into the crystal that can be used to study the time elapsed between the mixing event (diffusion starts) and eruption (diffusion effectively stops). Fe-Mg diffusive exchange in olivine (i.e., Fe-Mg interdiffusion) is a particularly powerful chronometer because the rate of diffusion is well known (Dohmen and Chakraborty, 2007), timescales of days to years can be studied (e.g., Kahl et al., 2011), and profiles can be measured at high spatial resolution via BSE imaging (Streck, 2008).

Olivine composition and zonation patterns studied here indicate magma mixing. Therefore, we can extract a temporal record of the mixing event(s) by modeling $\mathrm{Fe}-\mathrm{Mg}$ interdiffusion. Most evaluated crystals contain simple zonation patterns (i.e., reverse or normal zonation near the rim and a flat chemical gradient near the core). A few crystals ( 4 of 78 ) show interior zonation patterns that merged into the zonation pattern on the rim. For these cases, we modeled the dominant zonation pattern. Modeling was conducted using the DIPRA software (Girona and Costa, 2013), a finite difference code that solves Fick's second law of diffusion. Several parameters went into the calculation:

Initial concentration profile. Following mixing, the olivine zonation can be described as initially homogeneous (i.e., no crystal growth; Figs. 3a, b), step-function (i.e., "instantaneous" olivine growth; Fig. 3), or initially zoned (i.e., olivine growth, leaving a zoned profile). We did not consider the third case (initially zoned) because olivine crystallization, even if rapid, is thought to result in a homogeneous profile (e.g., Shea et al., 2015b). Additionally, we modeled profiles along different crystallographic axes and only consider results with timescales that overlap within uncertainty. To distinguish between initially homogeneous and step-function cases, we took two approaches. First, we evaluated the profile shape of a slow diffusing (>decades) element $(\mathrm{P})$. The effective partitioning of $P$ increases when crystal growth rate is high (Milman-Barris et al., 2008). Thus, a sharp increase in $\mathrm{P}_{2} \mathrm{O}_{5}$ implies rapid olivine growth (step-function) (e.g., Fig. 3c). Second, we evaluated the shape of the Fo profile. Where a zoned profile plateaus near the rim or the 

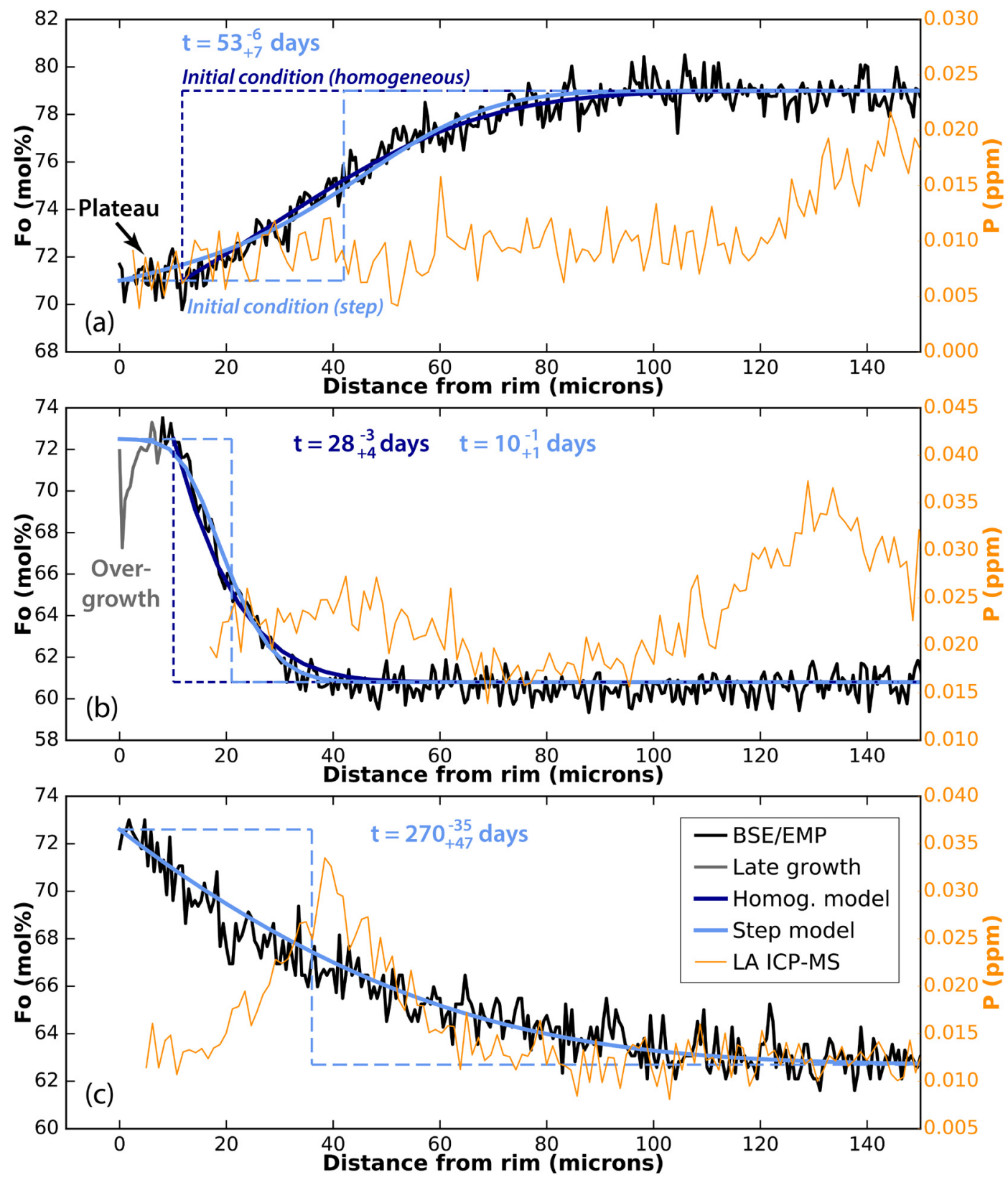

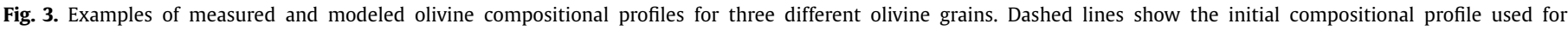

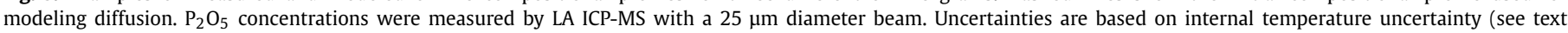

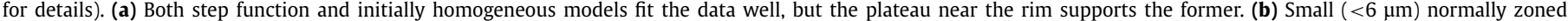

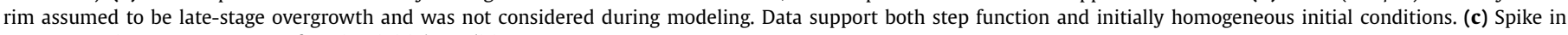
$P$ concentration supports a step function initial condition.

profile is strongly sigmoidal in shape, we assumed rapid olivine growth occurred (e.g., Fig. 3a). If we could not distinguish between initial conditions using these criteria, we modeled both initially homogeneous and step function cases. Where both cases yield consistent results for axes along different crystallographic directions, we present each as $t_{\min }$ (for step function) and $t_{\max }$ (for initially homogeneous). Where results for just one of the starting conditions was consistent or the initial condition could be inferred, one timescale is provided.

Crystallographic orientation. Diffusion along the $c$-axis of olivine is six times faster than along the $a$ - and $b$-axes (Dohmen and Chakraborty, 2007). We used EBSD results to constrain the orientation.
Temperature. We calculated equilibrium temperature of olivinemelt-inclusion pairs using the thermometer (eq. 4) of Putirka et al. (2007). To avoid uncertainty introduced by PEC/PEM corrections, we evaluated 10 bubble-free melt inclusions without significant PEC/PEM (i.e., equilibrium olivine within one Fo mol.\% of the host; Fig. A.2), which we assume to be representative of the mixed magma body. The average temperature, $1093^{\circ} \mathrm{C}$, is in good agreement with temperature from olivine-matrix-glass pairs (Fig. A.7). We consider the standard deviation of these temperature measurements $\left( \pm 8^{\circ} \mathrm{C}\right)$ as the internal uncertainty and the standard error of estimate (SEE) of the thermometer $\left( \pm 29^{\circ} \mathrm{C}\right)$ as the systematic uncertainty. We also calculated the entrapment temperature, using the measured host composition with the PEC/PEM corrected inclusion composition and $\mathrm{H}_{2} \mathrm{O}$ concentration determined by $\mathrm{S}-\mathrm{H}_{2} \mathrm{O}$ systematics (Fig. A.4), and the eruption temperature, 


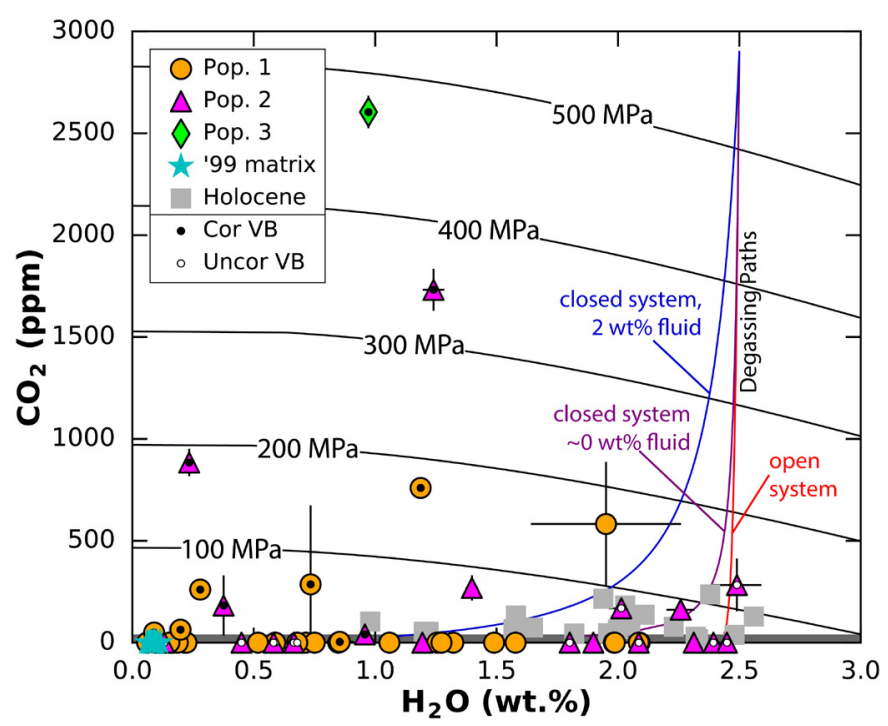

Fig. 4. $\mathrm{H}_{2} \mathrm{O}$ and $\mathrm{CO}_{2}$ content of melt inclusions and matrix glasses. Holocene data are from Zimmer et al. (2010). Melt inclusions showing $\mathrm{CO}_{2}$ concentrations below the detection limit for FTIR $\left(3^{*} s t d\right.$. dev -background $=40 \mathrm{ppm}$ ) are plotted along the $\mathrm{x}$-axis (i.e., $\mathrm{CO}_{2}=0 \mathrm{ppm}$ ). The detection limit is shown in dark gray. $\mathrm{CO}_{2}$ contents of melt inclusions with vapor bubbles that have been reconstructed using Raman data are indicated by black dots, and inclusions with vapor bubbles that have not been reconstructed are indicated by white dots. Inclusions without a vapor bubble do not have a dot. Error bars are $1 \sigma$ and include uncertainty of FTIR and Raman (when applicable) analyses. Isobars and degassing paths were calculated using Newman and Lowenstern (2002), assuming $\mathrm{SiO}_{2}=49 \mathrm{wt} . \%$ and $\mathrm{T}=1093^{\circ} \mathrm{C}$. Melt inclusions that plot at high values of $\mathrm{H}_{2} \mathrm{O}$ and low values of $\mathrm{CO}_{2}$ (i.e., below detection limit) indicate degassing occurs in a relatively open system (Newman and Lowenstern, 2002).

using measured inclusion composition with the calculated equilibrium olivine and measured $\mathrm{H}_{2} \mathrm{O}$ concentration. These results average to $1072{ }^{\circ} \mathrm{C}$ and $1095^{\circ} \mathrm{C}$, respectively, most falling within the SEE of the thermometer (Fig. A.7).

Pressure. Pressure has a minor effect on diffusion. For simplicity, we assumed a value of $90 \mathrm{MPa}$, which is consistent with results of solubility barometry.

Oxygen fugacity. We used the average result $(\mathrm{NNO}+0)$ from olivine-melt $\mathrm{V}$ partitioning calculations described above and shown in Fig. A.1a.

Diffusivity. Expressions for the diffusivity of Fe-Mg in olivine derived from DIPRA are based on experimentally calibrated models from the literature (Dohmen and Chakraborty, 2007). The effect of water on $\mathrm{Fe}-\mathrm{Mg}$ interdiffusion was assumed negligible because of the low water content ( $\sim 1$ wt.\%) of the system (Costa and Chakraborty, 2008).

The DIPRA software calculates error in diffusion time based on uncertainties in temperature and composition (i.e., analytical noise). We used both the internal and systematic uncertainties in temperature for error analysis. Uncertainty in oxygen fugacity is thought to have a minor effect on diffusion times ( $\pm 5 \%$ for the standard error of the mean of NNO measurements) and is not considered further.

We evaluated 148 individual profiles in 78 crystals (including 18 melt inclusion hosts), and 69 crystals had timescales between multiple profiles overlapping within uncertainty (Fig. 5). Crystals without consistent results, likely reflecting growth zonation or sectioning effects (Shea et al., 2015a), were excluded. For timescales, typical $1 \sigma$ internal uncertainty is about $14 \%$, whereas systematic uncertainty is $35-50 \%$.

\subsection{Modeling the depth of magma storage with vapor saturation pressure}

Volatile solubility in silicate melt strongly depends on pressure (Moore, 2008). Melt inclusions record the volatile content of a differentiating magma, thereby providing a tool to examine the depths of magma storage, provided two strict requirements are met. First, the entrapped melt was vapor-saturated. Second, $\mathrm{H}_{2} \mathrm{O}$ and $\mathrm{CO}_{2}$ contents are unchanged since entrapment. Inclusions show clear evidence of saturation with a mixed volatile phase. Compared to an index of crystallization (e.g., $\mathrm{K}_{2} \mathrm{O}$ ), $\mathrm{CO}_{2}$ does not behave incompatibly (Figs. A.5a, b). The second requirement provides a challenge. Inclusions rapidly lose (or gain) $\mathrm{H}_{2} \mathrm{O}$ by diffusion of $\mathrm{H}^{+}$through the host when a concentration gradient exists between the external melt and inclusion (Gaetani et al., 2012). Diffusive loss of $\mathrm{H}^{+}$becomes important during magma ascent as water degasses, increasingly at shallower depths (Fig. 4). The process can be examined by evaluating water contents of inclusions of variable size because small inclusions re-equilibrate more rapidly (Chen et al., 2013). No relationship exists between inclusion size and water content, implying that water loss during ascent is minor. Additionally, we modeled diffusive loss of $\mathrm{H}^{+}$from inclusions, using the model of Chen et al. (2013) modified by Rasmussen et al. (2017). Negligible water loss occurs ( $<0.1 \mathrm{wt} . \%)$, assuming minimum reasonable ascent rates $(0.1 \mathrm{~m} / \mathrm{s}$; Lloyd et al., 2013) and maximum storage depths (3 km; Fig. 6). However, longer term water loss is likely, indicated by $\mathrm{H}_{2} \mathrm{O}$ and $\mathrm{K}_{2} \mathrm{O}$ scatter (Fig. A.5a), which is probably the result of re-equilibration with the shallow magma during pre-eruptive storage.

Taking these observations into account, we calculated two pressures recorded by melt inclusions. First, we calculated the last pressure of equilibration (Pequil), reflected in the measured $\mathrm{H}_{2} \mathrm{O}$ contents of the inclusions. The assumption is that the inclusions stalled at this pressure long enough (> hours to days) for the inclusions to diffusively equilibrate to the $\mathrm{H}_{2} \mathrm{O}$ concentration of the external magma, and then erupted rapidly from this depth. We have shown that inclusion compositions are consistent with opensystem degassing (Figs. 4, A.6), whereby $\mathrm{CO}_{2}$ is nearly completely lost before $\mathrm{H}_{2} \mathrm{O}$ degasses. Therefore, the measured $\mathrm{H}_{2} \mathrm{O}$ content and $\mathrm{CO}_{2}=0 \mathrm{ppm}$ was used to calculate Pequil. Second, we calculated entrapment pressure (Pentrap), which requires that water contents to be corrected for the diffusive loss. Given that $S$ does not diffuse through olivine significantly over the $\sim 1$ yr timeframe of this eruptive system, and there is little evidence that significant portions enter vapor bubbles, we used $\mathrm{S}-\mathrm{H}_{2} \mathrm{O}$ systematics (Fig. A.4) to restore the initial $\mathrm{H}_{2} \mathrm{O}$ concentration. Restored $\mathrm{H}_{2} \mathrm{O}$ and measured $\mathrm{CO}_{2}$ were used to calculate the Pentrap. Vapor saturation pressures were modeled using Newman and Lowenstern (2002). Results for Pequil vary from 0.1-63 MPa, corresponding to depths of $<3 \mathrm{~km}$ (for $>2.2 \mathrm{~g} / \mathrm{cm}^{3}$ ), which is within the volcanic edifice, and Pentrap estimates vary from 10-500 MPa, corresponding to depths of $\sim 0-20 \mathrm{~km}$ (Fig. 6).

\section{Shear-wave splitting analysis}

In 1998-1999, Shishaldin was monitored by a permanent seismic network comprised of three Mark Products short-period seismic stations located within $10 \mathrm{~km}$ of the summit (Moran et al., 2002). One station (SSLS; Fig. 1) hosted a three-component sensor (MP L22-3D; $1 \mathrm{~Hz}$ corner) sampled at $100 \mathrm{~Hz}$, enabling analysis of shear-wave splitting (SWS) in regional (tectonic) earthquakes using a semi-automated method (Savage et al., 2010), detailed in Appendix B.

From 46 analyzed regional earthquakes during July 1998December 1999, we obtained 11 stable SWS measurements that allow us to make broad interpretations of precursory stress changes 


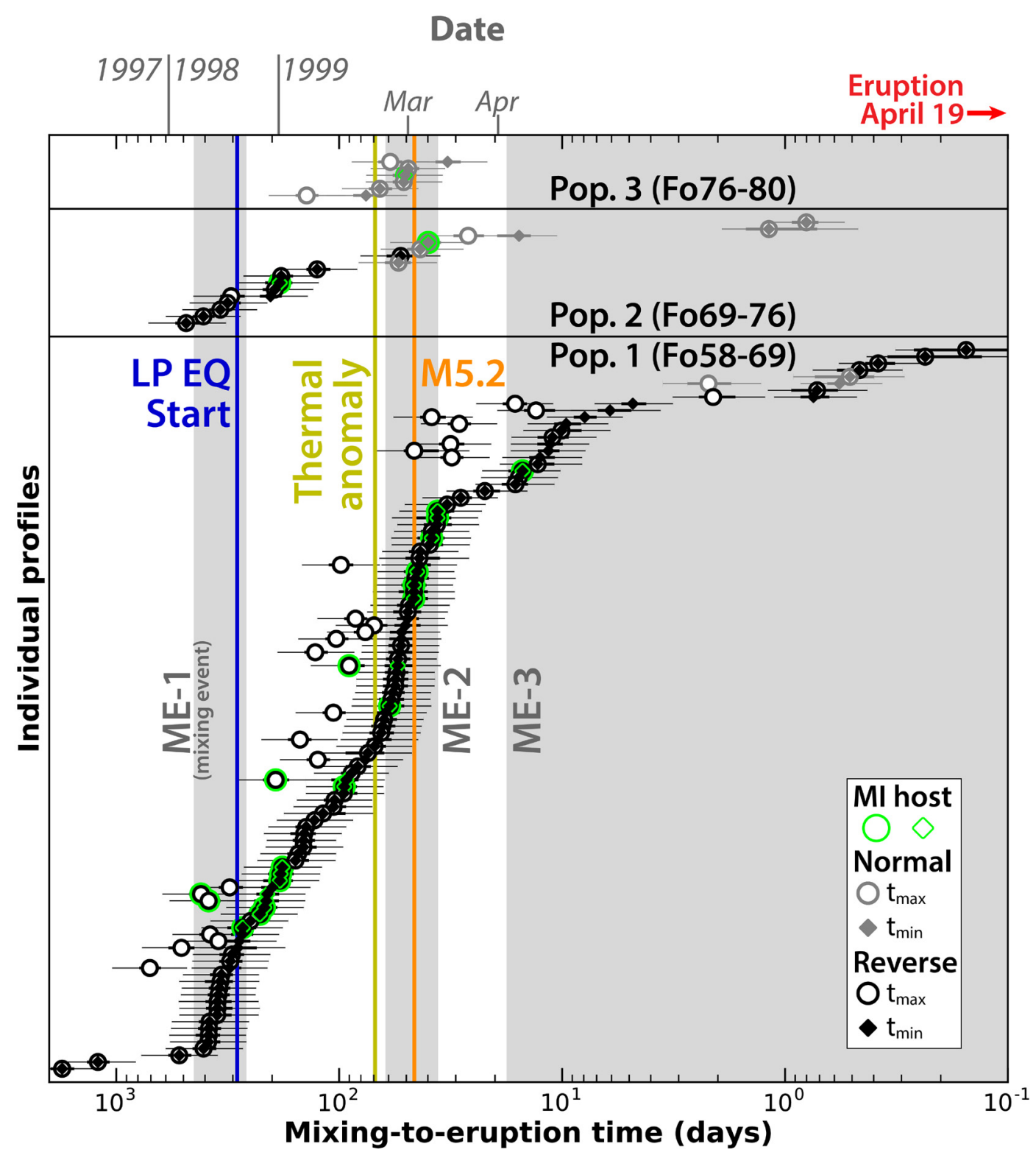

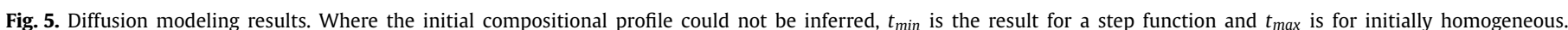

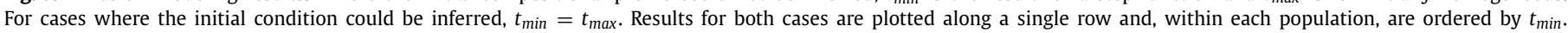

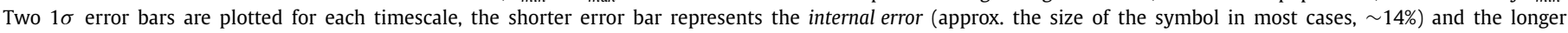

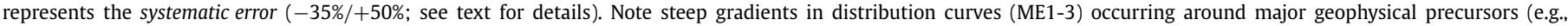
start of long period earthquakes, magnitude 5.2 earthquake).

in response to magma mixing and ascent (Fig. 7). The depths of the events are variable (12-65 km BSL; Fig. 7, Table C.8). Prior to mid-August 1998, fast wavelet orientations $(\Phi)$ are subparallel to regional maximum compression. From mid-August 1998 until the eruption, $\Phi$ measurements indicate a spatiotemporally heterogeneous local stress field orientation. In August 1998, delay times (dt) increase sharply from $0.1 \mathrm{~s}$ to $>0.4 \mathrm{~s}$ and $\Phi$ changes from subparallel to the regional maximum compression to perpendicular, coincident with the July LP swarm. Starting in February 1999, dt decreases sharply and $\Phi$ becomes variable, coincident with the observation of a thermal anomaly at the summit. Following the eruption, dt and $\Phi$ both return to background levels. The depth of the anisotropic region, which existed from August 1998 until the eruption in April 1999, is constrained to the depth range between the earthquake depth and the elevation of SSLS $(\sim 1 \mathrm{~km}$ above sea level). In most cases, the depth range spans the thickness of the crust (41 km; Janiszewski et al., 2013).

\section{Discussion}

8.1. Combining geochemical and geophysical observations of eruption run-up

Generally considered the earliest precursor to the 1999 eruption of Shishaldin, the July 1998 LP swarm spanned depths of $>20 \mathrm{~km}$ to the surface, providing captivating, yet tenuous, evidence for magma recharge from the mid crust (Moran et al., 2006; Power et al., 2004). LP earthquakes are typically associated with magma movement (Power et al., 2004), although other source mechanisms have been proposed (Aso and Tsai, 2014). InSAR images spanning this period do not show inflation (Moran et al., 2006). Therefore, the recharge interpretation would benefit from crystal clock corroboration. The longest mixing timescales we find form a weak peak at $\sim 350$ (ME-1, Fig. 8e), \pm 40 days (internal uncertainty) or $-120 /+175$ days (systematic uncertainty). 

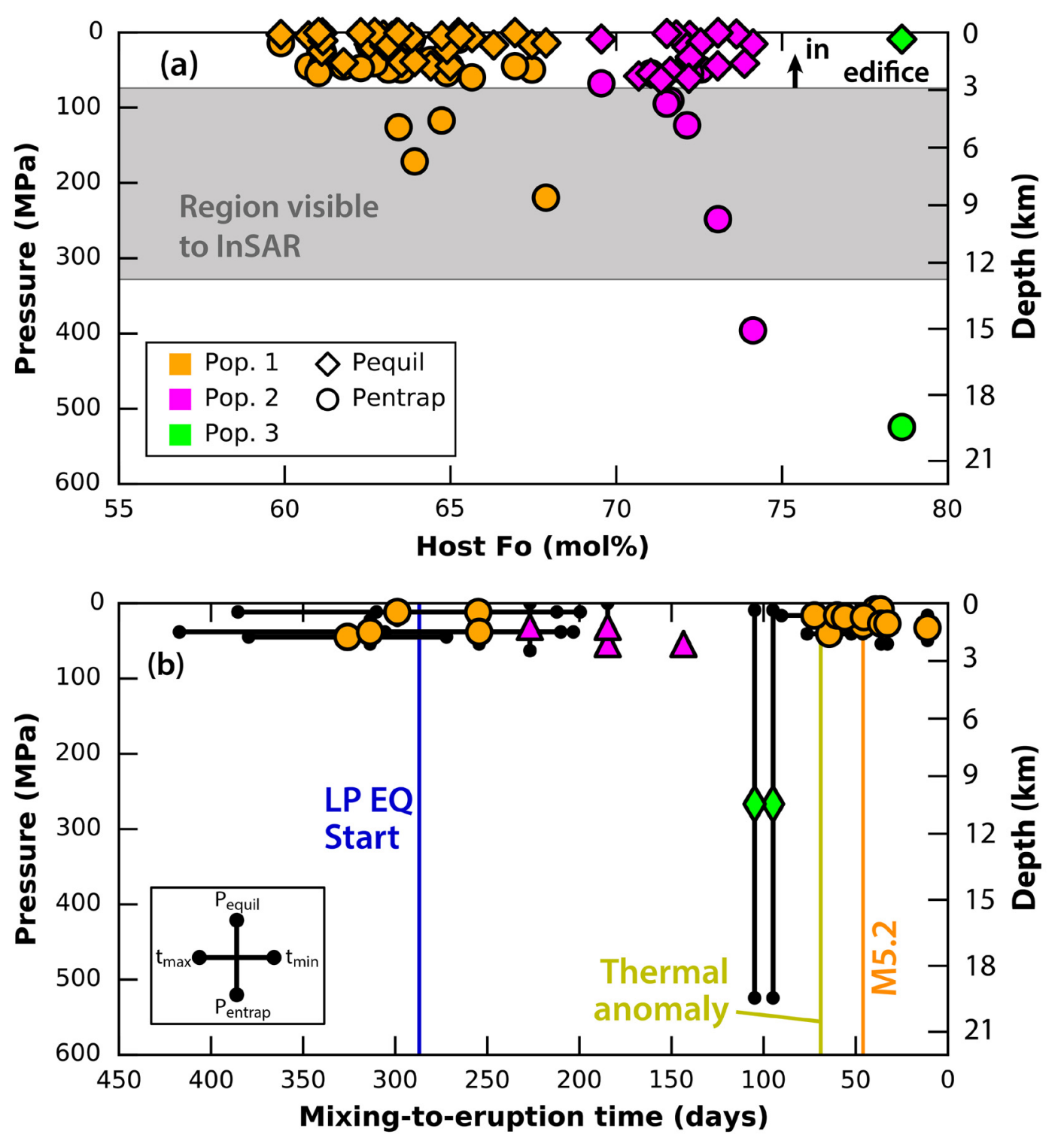

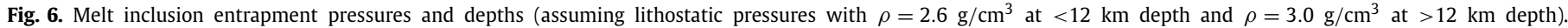

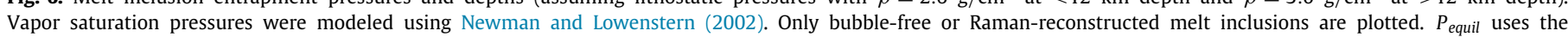

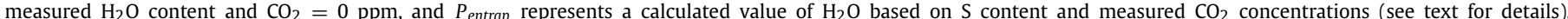

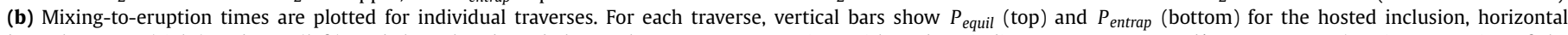

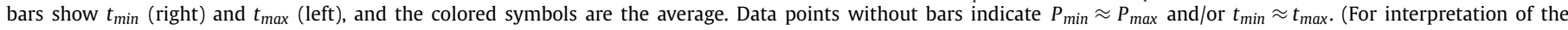
references to color in this figure, the reader is referred to the web version of this article.)

We attribute this peak to mixing that followed the July DLP swarm ( 290 days) (Fig. 9a). A possible reason for the offset is that our temperature estimates are for the magma immediately prior to eruption. Temperatures of earlier magmas are less wellconstrained.

A month after the July LP swarm, we observe a change in SWS (Fig. 7). An increase in dt was accompanied by a $\sim 90^{\circ}$ change in $\Phi$ from parallel to regional maximum compressive stress (NUVEL-1A; DeMets et al., 1994) to nearly perpendicular. A similar change in SWS observed during the run-up to the 2009 eruption of Redoubt volcano was suggested to result from stress field reorientation following magmatic intrusion (Roman and Gardine, 2013). Pressurization can result from addition of new magma or second boiling of magma already in place. Diffusion chronometry does not give a strong indication of mixing during the August 1998 change in dt (Fig. 8e), although the first peak in mixing timescales (ME-1) at 350 days could be shifted to this event (260 days) if the temperatures are under-estimated by 20 degrees (within the systematic uncertainty). We find it more likely, however, that ME-1 coincides with the July LP swarm, which is closer in time to the ME-1 peak. The two earthquakes bracketing the change in SWS occurred at $57 \mathrm{~km}$ depth (Fig. 7), giving a maximum depth for the intrusion. Therefore, the pressurization associated with the stress field change could have occurred without mixing (or without a crystal clock record), perhaps deep in the system, or as a delayed response to the mixing event (i.e., due to second boiling).

A second swarm of LP earthquakes occurred in OctoberNovember 1998, and after, there were few geophysical signs of unrest until February 1999 (Fig. 8). During this time, a few crystal clocks, roughly one every five days, were activated (Fig. 8e). One possibility is that there was quiescence in the magmatic system during this time, and the few diffusion timescales we see are due to sectioning effects (Shea et al., 2015a). However, if this were the case, we would expect to see a pseudo-exponential decay in the number of timescales following the true mixing events. The observed distribution is more irregular. More likely scenar- 


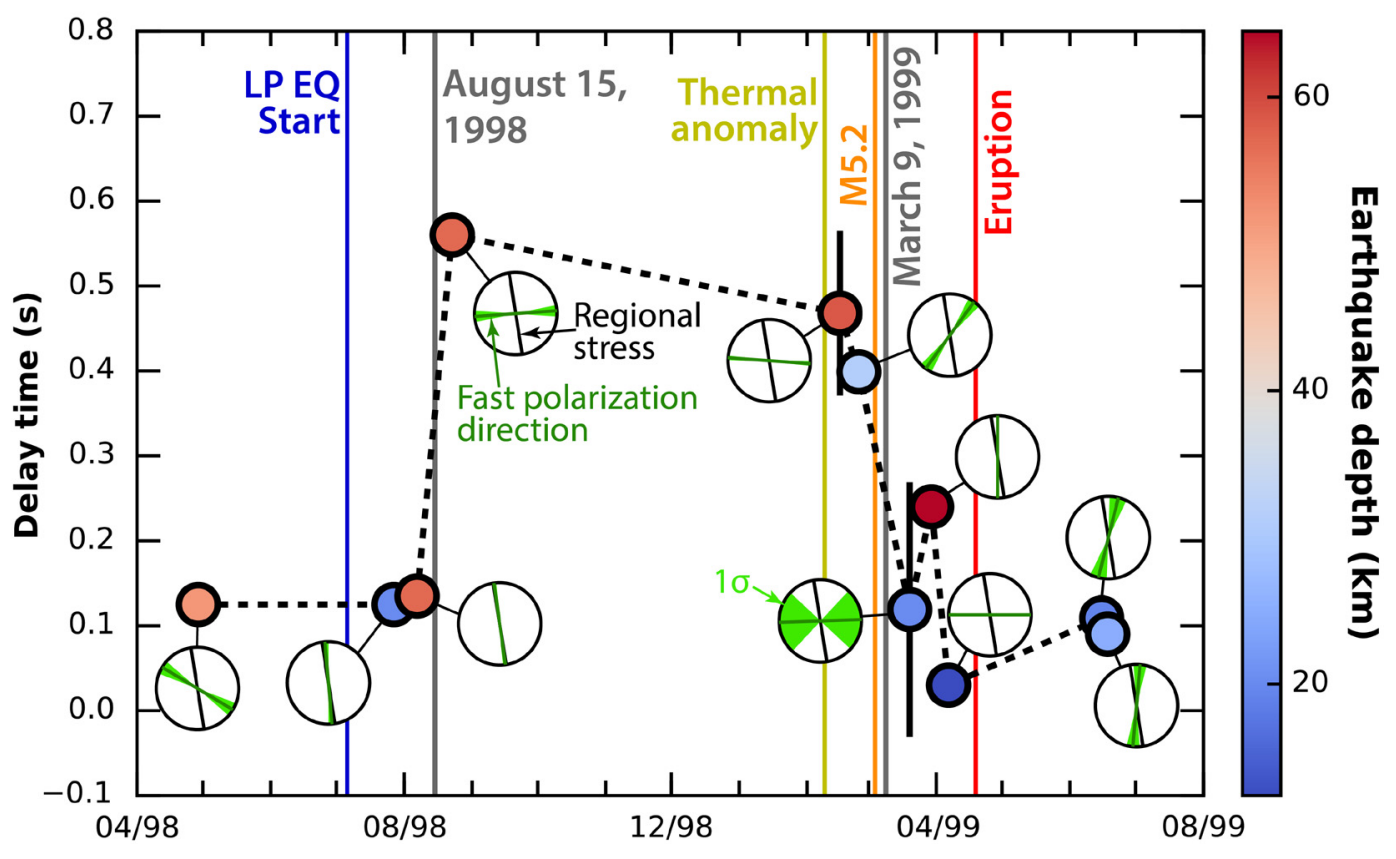

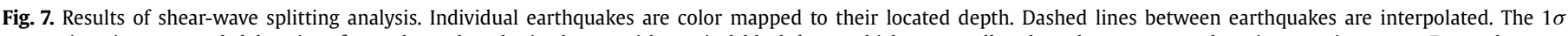

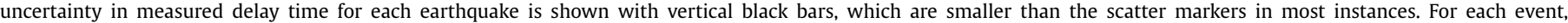

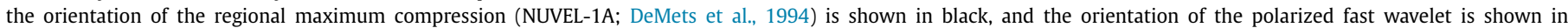

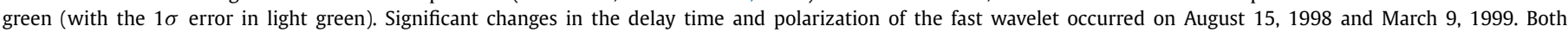

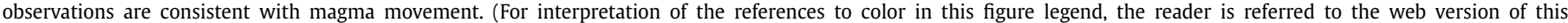
article.)

ios include small recharge events or mixing during destabilization and rearrangement (Fig. 9b). Winter storms could have increased instrument noise and obscured subtle seismic signals of unrest. Additionally, the feeding system may have become mechanically weak and less prone to seismicity after repeated intrusion (Sparks, 2003).

February and March of 1999 brought signs of impending eruption (Fig. 8). On February 9, satellite observations detected a thermal anomaly in the summit crater (Dehn et al., 2002). Around this time, LP events were recorded, tremor became continuous, and vigorous steam plumes were emitted (Nye et al., 2002). We also observed a concurrent decrease in dt (Fig. 7), suggesting a decrease in pressurization below the elevation of station SSLS. There is not strong evidence for significant mixing at that time (Fig. 8e). These observations are consistent with upward transfer of magma to a shallower reservoir (Fig. 9c). On March 4, there was a shallow M5.2 tectonic earthquake that has been attributed to magmatic intrusion (Moran et al., 2002). Concurrently, the thermal anomaly grew in strength and, based on zenith angle widening, apparently ascended in the conduit until March 21, when Strombolian activity may have commenced (Dehn et al., 2002; Fig. 8c). A major peak (ME-2 $=\sim 50 \pm 7$ days) in mixing timescales is coincident with the M5.2 earthquake (46 days), which gives strong evidence that a large pulse of new magma charged the shallow system at the time (ME-2; Fig. 8d). However, the systematic uncertainty could shift this peak by \pm 21 days, leaving some uncertainty on the timing. Also at the time of the M5.2, dt dropped to nearly background levels (Figs. 7, 8c), but measurements of $\Phi$ were more variable over the next few weeks. These observations are most consistent with the upward propagation of the pressure source to an elevation above SSLS, but because the depths of the earthquakes are variable during this time, the length of the ray path could have some effect on the signal. Taken together, we have evidence of upward magma migration in the shallow system in early February (Fig. 9c), and a clear indication that a large intrusion that occurred in late February to early March (Fig. 9d).
Unrest continued after the M5.2 earthquake. Tremor gradually increased in magnitude, punctuated by a few spikes and drops, possibly indicating Strombolian activity (Thompson et al., 2002). There is a lull in crystal clock initiation until approximately a week prior to eruption when there is an uptick in mixing timescales (ME-3 = 10 \pm 1 days; April 9; Figs. 5, 8d), which is coincident with a sharp increase in tremor that occurred on April 7 (Nye et al., 2002). ME-3 likely represents a new magma injection or vigorous mixing of heterogeneous domains prior to eruption (Fig. 9e). The latter is supported by the irregular nature of the zonation patterns (ME-3 zonation patterns in population 1 are both reverse and normally zoned). About a week later (April 17), the first confirmed eruptive activity began, consisting of small Strombolian bursts (Nye et al., 2002). On April 19, the sub-Plinian eruption occurred.

\subsection{Why does Shishaldin apparently not deform?}

Despite 43 million $\mathrm{m}^{3}$ of tephra being ejected, interferograms spanning the 1999 eruption of Shishaldin (September 1998 to May 1999; Fig. 8c) showed negligible eruption-related deformation (Lu and Dzurisin, 2014; Moran et al., 2006), consistent with the long-term lack of observable deformation (Lu and Dzurisin, 2014; Moran et al., 2006). Synthetic interferograms simulating withdrawal of the appropriate volume of melt from a Mogi source at shallow depths $(0 \mathrm{~km}$ BSL) show deformation above detection limit (Lu and Dzurisin, 2014). Evaluating the 1995 and 1999 eruptions of Shishaldin, Moran et al. (2006) suggest several possible explanations for the apparent lack of deformation: (1) deformation took place and was recovered in the time between satellite passes ( $\sim 9$ months), (2) deformation was focused in regions where InSAR is insensitive to deformation (i.e., $>10 \mathrm{~km}$ BSL or in the edifice), or (3) there was no deformation. They favored the first two ideas, suggesting recharge originates from deep ( $>10 \mathrm{~km} \mathrm{BSL})$ and operates on timescales outside the temporal resolution of InSAR, and associated deformation occurred in regions where the deformation signal was dampened. Critical to testing this hypothesis is 

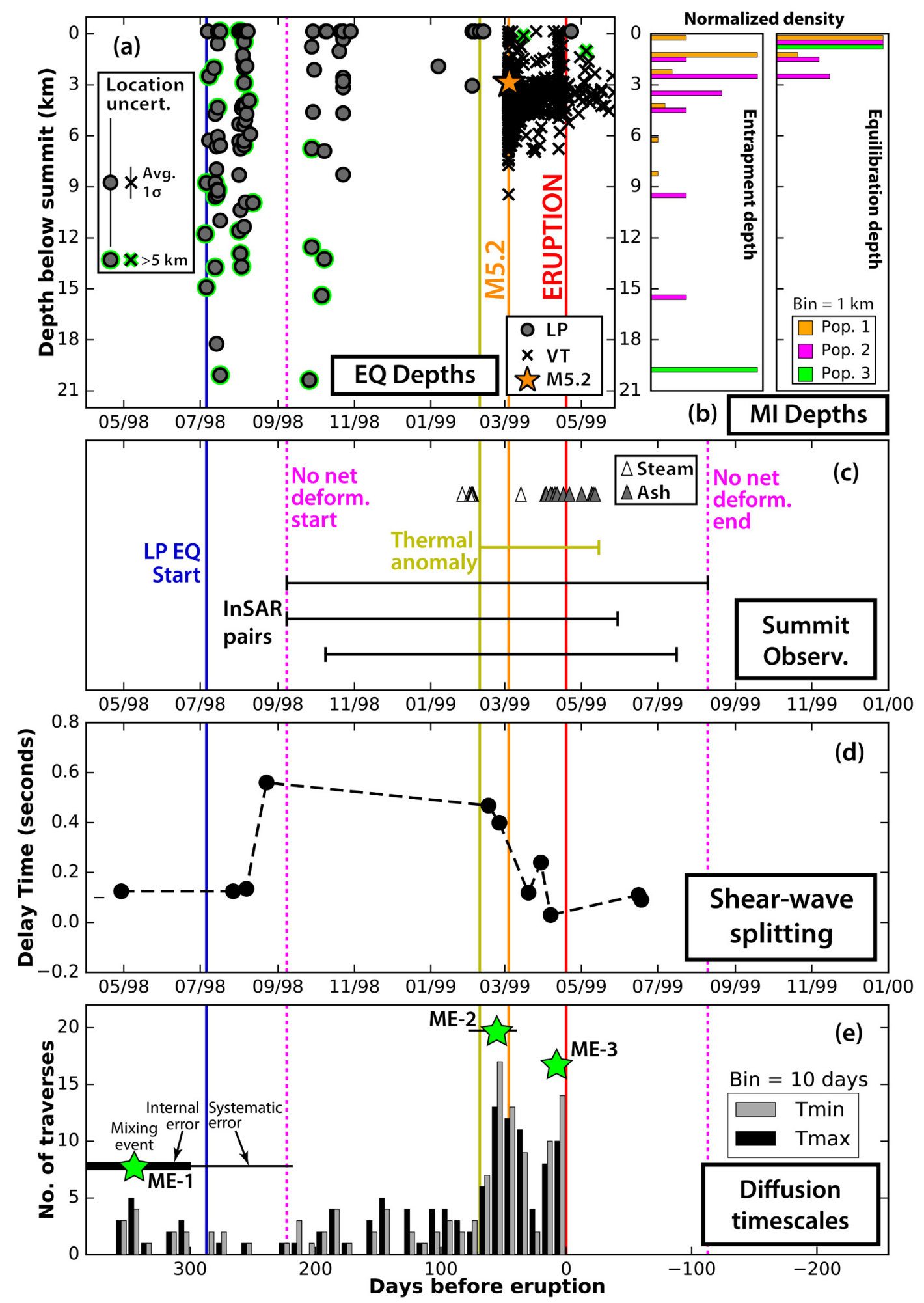

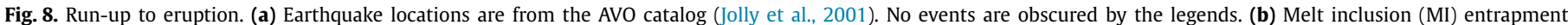

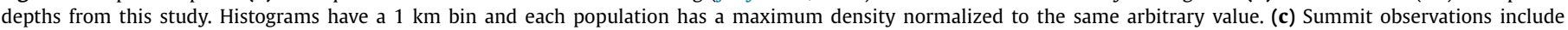

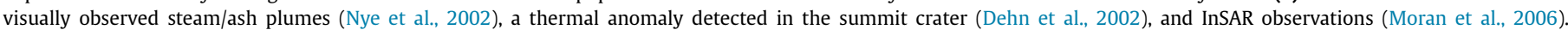

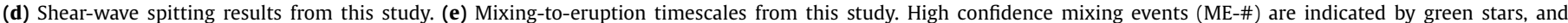

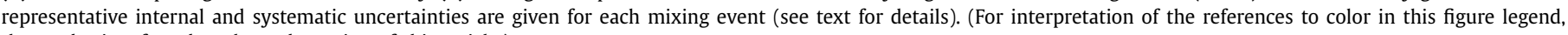
the reader is referred to the web version of this article.)

understanding the location of magmas in space and time prior to eruption.

Geochemical and geophysical observations discussed here provide a detailed pre-eruptive history of the magmas. Recharge oc- curred in July 1998 (ME-1; Fig. 9a) and small intrusions may have continued sporadically (Fig. 9b) until February-March 1999 (ME-2), when a substantial influx of magma to the shallow storage region occurred (Fig. 9d). The July recharge magma was likely 


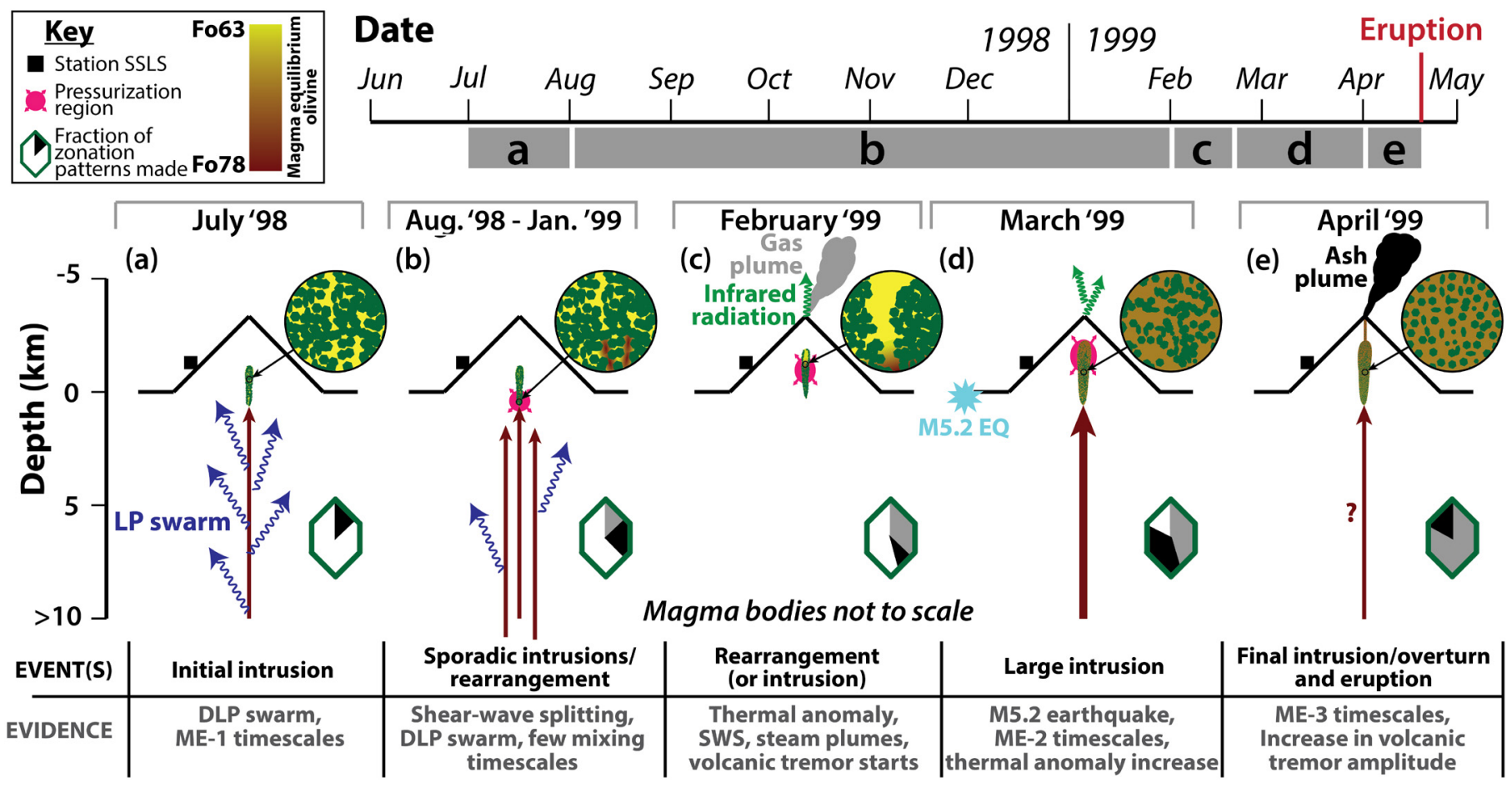

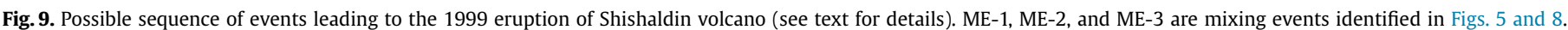

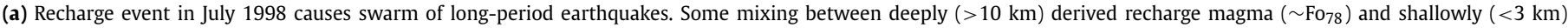

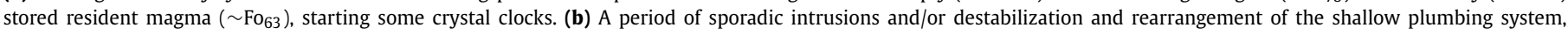

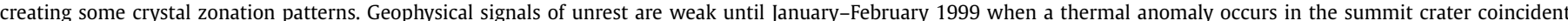

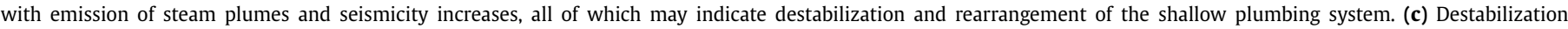

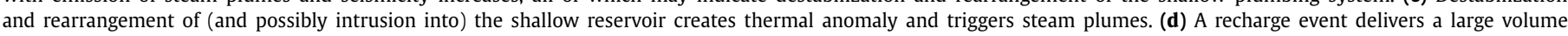

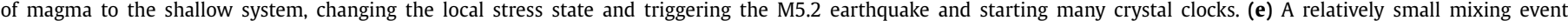
triggers the eruption within a few days.

derived from $>20 \mathrm{~km}$ depth, indicated by the maximum depth of LP swarms (Fig. 8a), and it resulted in pressurization of an area below the elevation of station SSLS (Figs. 7, 9b). Part of the February-March recharge may have been sourced from a similar depth as the July recharge, given the entrapment pressure (equivalent to $\sim 20 \mathrm{~km}$ depth) of the single melt inclusion that is associated with the recharge magma (Population 3, Figs. 6, 8b). Magma in the pressurization region also likely ascended during this time, which resulted in the upward migration of the pressure source and causing the decline in dt measured at SSLS (Figs. 7, 9d). Mixing associated with the July and February-March recharge events occurred between recharge magma and shallow olivine stored within the edifice (Pentrap of Population 1 are nearly all in the edifice; Figs. 6a, 8b). Corroborating this notion are mixing timescales in olivines with shallowly entrapped inclusions that might date back to the July LP swarm (Fig. 6b). Additionally, population 2 olivines may represent the mixing reservoir, with entrapment depths constraining the mixing depth to mostly within the edifice (Fig. 6a). Together, we have evidence of recharge initiating at depths of $\geq 20 \mathrm{~km}$, which led to mixing at shallow depths (within edifice).

The volumetric proportion of resident and recharge magmas can be approximated for the two end-member mixing scenarios considered: (1) mixing between more- and less-evolved magmas (represented by populations 1 and 3) or (2) mixing between an intermediate composition magma (i.e., population 2) and preexisting olivine. In the first case, melt ratios can be approximated by evaluating the mixing ratio of the melts in equilibrium with the modes of populations $1\left(\mathrm{Fo}_{63}\right)$ and $3\left(\mathrm{Fo}_{78}\right)$ cores required to create the rim composition mode $\left(\mathrm{Fo}_{68}\right)$, which indicates a $3: 2$ ratio of resident to recharge melt. Alternatively, the second case requires that all the melt was delivered during the recharge. In both cases, the recharge magma contributes substantially to the volume of erupted magma.

These results indicate that InSAR images used by Moran et al. (2002) were blind to the deformation in both space and time. Magmas feeding the eruption were sourced from depths of $<3 \mathrm{~km}$ (in the edifice) or $>10 \mathrm{~km} \mathrm{BSL}$, and most of the recharge magma moved between the deep and shallow reservoirs in the time between satellite passes. It is unclear if deformation would have been detected if measurements were made with modern satellites or ground-based sensors, which may offer greater sensitivity or a decreased repeat interval of measurements.

The long-term lack of deformation at Shishaldin is yet to be explained. One possibility is the absence of a permanent shallow storage region at Shishaldin (Moran et al., 2006; Lu and Dzurisin, 2014). However, LP swarms during repose intervals are common (Fig. A.8), which are possibly related to upward melt migration. Shallow, inter-eruption storage has been suggested (Cusano et al., 2015). If this occurs, long-term lack of deformation may relate to the geometry of magma storage. Vertically oriented reservoirs result in minor surface deformation relative to point-source approximations (Ebmeier et al., 2013), which could explain the absence of observations of significant deformation at Shishaldin. Assuming water loss during ascent is minimal (see 6.2), melt inclusions evaluated here indicate storage at a range of depths prior to eruption (Pequil, Fig. 6a), supporting a vertically oriented system. One possibility is that shallow magma storage occurs in a conduit, which has been suggested for other open-system volcanoes (Chaussard et al., 2013). If so, an approximation of the dimensions can be made by taking the volume of erupted material $\left(1.4 \times 10^{7} \mathrm{~m}^{3}\right.$ DRE; Stelling et al., 2002) and the vertical extent of pre-eruptive magma storage of $2.5 \mathrm{~km}$ indicated by Pequil (Fig. 6a), which yields a relatively large conduit radius of $\sim 42 \mathrm{~m}$. 


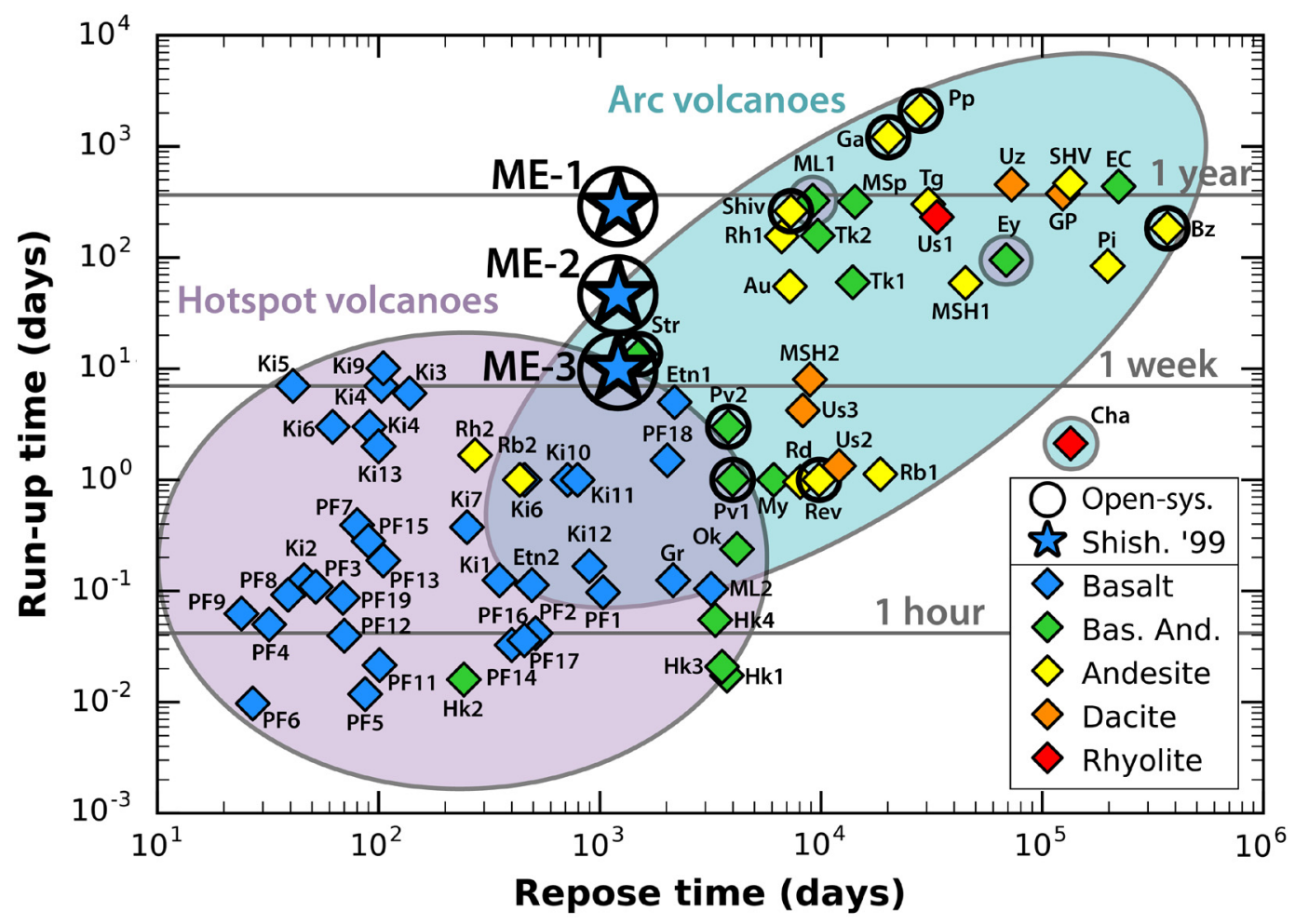

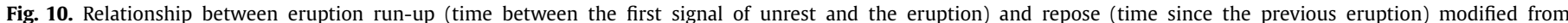

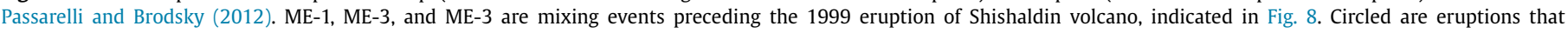

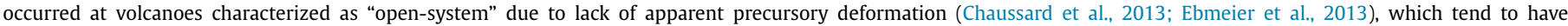

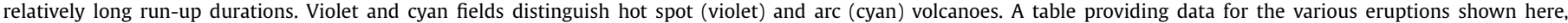

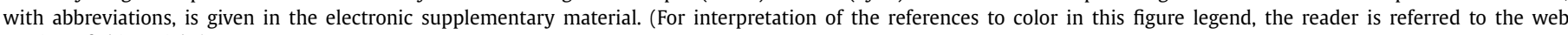
version of this article.)

This might suggest the storage region was more extensive than a conduit.

\subsection{When does eruption run-up begin?}

Identifying the timing and nature of magmatic events that precede eruption informs our understanding of eruption triggers and improves hazard assessment. For the 1999 eruption of Shishaldin, most consider the July LP swarm as the earliest sign of unrest (Nye et al., 2002; Power et al., 2004). However, the role the July LP events played in eruption run-up is neither simple, nor direct. Similar LP swarms are common to Shishaldin, and most do not lead to eruption (Fig. A.7), consistent with studies of crystal residence times that reflect several pulses of magmatic input to crustal reservoirs during repose intervals (Cooper and Kent, 2014). Following the second LP swarm in November, there was a period of relative geophysical and petrological quiescence (Fig. 8), with perhaps some small recharge events (Fig. 9b). After this brief repose, signals of unrest begin again in January-February 1999, culminating in a high flux recharge event in February-March 1999 (ME-2; Fig. 8). Interestingly, there were relatively few seismic signs of recharge until the M5.2 earthquake except for a few longperiod earthquakes (Fig. 8a) and tremor that was first recognized in mid-January (Thompson et al., 2002). It is possible that the July recharge "cleared the way", opening a path for magmas to later ascend aseismically. Borrowing terminology from Putirka (2017), we might categorize the July LP swarm and mixing event (ME-1) as being the start of the "proximal" run-up, whereas the FebruaryMarch recharge (ME-2) was the start of the "immediate" run-up when signals of unrest became continuous, and a final mixing event (ME-3) may have led to the onset of eruption.
Regardless of the event that best marks the beginning of unrest (e.g., ME-1, ME-2, ME-3), or whether a discrete event could do so, Shishaldin had a long run-up relative to those defined seismically with a similar repose interval, especially compared to other basaltic eruptions (Fig. 10). Due to the long-term lack of observed deformation, Shishaldin has been characterized as an open-system volcano (Lu and Dzurisin, 2014). One interpretation of this behavior is that deeply derived magma moves into the shallow system, pressurizing the shallow reservoir immediately prior to eruption (Ebmeier et al., 2013; Lu and Dzurisin, 2014). It is possible that the long duration of run-up at Shishaldin, and at some other opensystem volcanoes (Fig. 10), reflects the time required to transfer erupted mass from a deep reservoir to a shallow staging area. Alternatively, closed-system eruptions may be fed from a shallow reservoir (Chaussard et al., 2013). Some other open-system volcanoes have been suggested to have similarly deeply rooted plumbing systems with minor shallow reservoirs (e.g., Cleveland, Galeras, Pavlof; Lu and Dzurisin, 2014). Others show evidence for established shallow reservoirs (e.g., Popocatépetl, Colima, and Merapi; Chaussard et al., 2013). Therefore, the process of mass transfer from deep reservoirs may be important at only some open-system volcanoes, which might lead to long run-up durations at these locations.

\section{Conclusion}

The synergy between geochemical and geophysical observations explored here demonstrate the effectiveness of this approach for understanding magmatic activity during unrest. We have identified three phases of run-up to the 1999 eruption of Shishaldin volcano. A swarm of LP earthquakes that occurred 9 months prior to eruption coincides with magma mixing timescales, marking the 
beginning of the "proximal" run-up. Major mixing events, supported by geochemical and geophysical observations, occurred at $\sim 50$ and $\sim 10$ days prior to eruption, constituting the "immediate" run-up.

We attribute the lack of observable deformation associated with the 1999 eruption to inadequate spatial and temporal resolution of the InSAR measurements. Melt inclusion barometry and the depth of LP events indicate that most of the erupted magma was sourced from depths outside of InSAR sensitivity ( $<0 \mathrm{~km}$ and $>10 \mathrm{~km} \mathrm{BSL}$ ), and diffusion chronometry results show that most magma movement through the $0-10 \mathrm{~km}$ BSL occurred in the time between satellite passes. Additionally, inclusion equilibration depths imply storage in a vertical reservoir, providing a possible explanation for the longer-term lack of observed deformation at Shishaldin.

The run-up duration for the 1999 eruption of Shishaldin $(\sim 9$ months from ME-1, $\sim 50$ days from ME-2) is long relative to seismically determined run-up durations (hours to days) for other basaltic eruptions (Passarelli and Brodsky, 2012). Some other opensystem volcanoes have relatively long run-up durations. A possible explanation is that open-system volcanoes require significant mass transfer from depth prior to eruption, leading to a longer runup. Closed-system volcanoes may source a greater proportion of magma from shallow reservoirs.

\section{Acknowledgements}

We would like to give thanks to our reviewers, Margaret Hartley and one anonymous reviewer, and our editor, Tamsin Mather, for thoughtful comments that improved the paper. We would like to express great gratitude to Philipp Ruprecht, who helped reduce the olivine data, and Glenn Thompson, who provided continuous seismic data from Shishaldin. Special thanks are also due to Louise Bolge, Adrian Fiege, W. Henry Towbin, Lowell Moore, and Charles Farley, who helped with analyses. This work was supported by the NSF GeoPRISMS program [grant numbers EAR-1456814 and EAR-1456939]. Additional support came from the Don Richter Memorial Scholarship awarded to DJR by the Alaska Geological Society.

\section{Appendix. Supplementary material}

Supplementary material related to this article can be found online at https://doi.org/10.1016/j.epsl.2018.01.001.

\section{References}

Aso, N., Tsai, V.C., 2014. Cooling magma model for deep volcanic long-period earthquakes. J. Geophys. Res., Solid Earth 119, 8442-8456.

Canil, D., 2002. Vanadium in peridotites, mantle redox and tectonic environments: Archean to present. Earth Planet. Sci. Lett. 195, 75-90.

Chaussard, E., Amelung, F., Aoki, Y., 2013. Characterization of open and closed volcanic systems in Indonesia and Mexico using InSAR time series. J. Geophys. Res., Solid Earth 118, 3957-3969.

Chen, Y., Provost, A., Schiano, P., Cluzel, N., 2013. Magma ascent rate and initial water concentration inferred from diffusive water loss from olivine-hosted melt inclusions. Contrib. Mineral. Petrol. 165, 525-541.

Cooper, K.M., Kent, A.J.R., 2014. Rapid remobilization of magmatic crystals kept in cold storage. Nature 506, 480-483.

Costa, F., Chakraborty, S., 2004. Decadal time gaps between mafic intrusion and silicic eruption obtained from chemical zoning patterns in olivine. Earth Planet. Sci. Lett. 227, 517-530.

Costa, F., Chakraborty, S., 2008. The effect of water on Si and O diffusion rates in olivine and implications for transport properties and processes in the upper mantle. Phys. Earth Planet. Inter. 166, 11-29.

Cusano, P., Palo, M., West, M.E., 2015. Long-period seismicity at Shishaldin volcano (Alaska) in 2003-2004: indications of an upward migration of the source before a minor eruption. J. Volcanol. Geotherm. Res. 291, 14-24.

Dehn, J., Dean, K.G., Engle, K., Izbekov, P., 2002. Thermal precursors in satellite images of the 1999 eruption of Shishaldin Volcano. Bull. Volcanol. 64, 525-534.
DeMets, C., Gordon, R.G., Argus, D.F., Stein, S., 1994. Effect of recent revisions to the geomagnetic reversal time scale on estimates of current plate motions. Geophys. Res. Lett. 21, 2191-2194.

Dohmen, R., Chakraborty, S., 2007. Fe-Mg diffusion in olivine II: point defect chemistry, change of diffusion mechanisms and a model for calculation of diffusion coefficients in natural olivine. Phys. Chem. Miner. 34, 409-430.

Ebmeier, S.K., Biggs, J., Mather, T.A., Amelung, F., 2013. On the lack of InSAR observations of magmatic deformation at Central American volcanoes. J. Geophys. Res., Solid Earth 118, 2571-2585.

Esposito, R., Lamadrid, H.M., Redi, D., Steele-MacInnis, M., Bodnar, R.J., Manning, C.E., De Vivo, B., Cannatelli, C., Lima, A., 2016. Detection of liquid $\mathrm{H}_{2} \mathrm{O}$ in vapor bubbles in reheated melt inclusions: implications for magmatic fluid composition and volatile budgets of magmas? Am. Mineral. 101, 1691-1695.

Gaetani, G.A., O'Leary, J.A., Shimizu, N., Bucholz, C.E., Newville, M., 2012. Rapid reequilibration of $\mathrm{H}_{2} \mathrm{O}$ and oxygen fugacity in olivine-hosted melt inclusions. Geology 40, 915-918.

Girona, T., Costa, F., 2013. DIPRA: a user-friendly program to model multi-element diffusion in olivine with applications to timescales of magmatic processes. Geochem. Geophys. Geosyst. 14, 422-431.

Hartley, M.E., Maclennan, J., Edmonds, M., Thordarson, T., 2014. Reconstructing the deep $\mathrm{CO}_{2}$ degassing behaviour of large basaltic fissure eruptions. Earth Planet. Sci. Lett. 393, 120-131.

Janiszewski, H.A., Abers, G.A., Shillington, D.J., Calkins, J.A., 2013. Crustal structure along the Aleutian island arc: new insights from receiver functions constrained by active-source data. Geochem. Geophys. Geosyst. 14, 2977-2992.

Jolly, A.D., Stihler, S.D., Power, J.A., Lahr, J.C., Paskievitch, John, Tytgat, Guy, Estes, Steve, Lockheart, A.D., Moran, S.C., McNutt, S.R., Hammond, W.R., 2001. Cata$\log$ of Earthquake Hypocenters at Alaskan Volcanoes: January 1, 1994 through December 31, 1999. U.S. Geological Survey Open-File Report 01-0189, 22 p.

Kahl, M., Chakraborty, S., Costa, F., Pompilio, M., 2011. Dynamic plumbing system beneath volcanoes revealed by kinetic modeling, and the connection to monitoring data: an example from Mt. Etna. Earth Planet. Sci. Lett. 308, 11-22.

Kress, V.C., Carmichael, I.S.E., 1991. The compressibility of silicate liquids containing $\mathrm{Fe}_{2} \mathrm{O}_{3}$ and the effect of composition, temperature, oxygen fugacity and pressure on their redox states. Contrib. Mineral. Petrol. 108, 82-92.

Lamadrid, H.M., Moore, L.R., Moncada, D., Rimstidt, J.D., Burruss, R.C., Bodnar, R.J., 2017. Reassessment of the Raman $\mathrm{CO}_{2}$ densimeter. Chem. Geol. 450, 210-222.

Lloyd, A.S., Plank, T., Ruprecht, P., Hauri, E.H., Rose, W., 2013. Volatile loss from melt inclusions in pyroclasts of differing sizes. Contrib. Mineral. Petrol. 165, 129-153.

Lu, Z., Dzurisin, D., 2014. InSAR Imaging of Aleutian Volcanoes, InSAR Imaging of Aleutian Volcanoes: Monitoring a Volcanic Arc from Space. Springer Berlin Heidelberg, Berlin, Heidelberg, pp. 87-345.

Milman-Barris, M.S., Beckett, J.R., Baker, M.B., Hofmann, A.E., Morgan, Z., Crowley, M.R., Vielzeuf, D., Stolper, E., 2008. Zoning of phosphorus in igneous olivine. Contrib. Mineral. Petrol. 155, 739-765.

Moore, G., 2008. Interpreting $\mathrm{H}_{2} \mathrm{O}$ and $\mathrm{CO}_{2}$ contents in melt inclusions: constraints from solubility experiments and modeling. Rev. Mineral. Geochem. 69, 333-362.

Moore, L.R., Gazel, E., Tuohy, R., Lloyd, A.S., Esposito, R., Steele-MacInnis, M., Hauri, E.H., Wallace, P.J., Plank, T., Bodnar, R.J., 2015. Bubbles matter: an assessment of the contribution of vapor bubbles to melt inclusion volatile budgets. Am. Mineral. $100,806-823$.

Moran, S.C., Stihler, S., Power, J.A., 2002. A tectonic earthquake sequence preceding the April-May 1999 eruption of Shishaldin Volcano, Alaska. Bull. Volcanol. 64, 520-524.

Moran, S.C., Kwoun, O., Masterlark, T., Lu, Z., 2006. On the absence of InSAR-detected volcano deformation spanning the 1995-1996 and 1999 eruptions of Shishaldin Volcano, Alaska. J. Volcanol. Geotherm. Res. 150, 119-131.

Newcombe, M.E., Fabbrizio, A., Zhang, Y., Ma, C., Le Voyer, M., Guan, Y., Eiler, J.M., Saal, A.E., Stolper, E.M., 2014. Chemical zonation in olivine-hosted melt inclusions. Contrib. Mineral. Petrol. 168, 1030.

Newman, S., Lowenstern, J.B., 2002. VolatileCalc: a silicate melt- $\mathrm{H}_{2} \mathrm{O}-\mathrm{CO}_{2}$ solution model written in Visual Basic for excel. Comput. Geosci. 28, 597-604.

Nye, C., Keith, T., Eichelberger, J., Miller, T., McNutt, S., Moran, S., Schneider, D., Dehn, J., Schaefer, J., 2002. The 1999 eruption of Shishaldin Volcano, Alaska: monitoring a distant eruption. Bull. Volcanol. 64, 507-519.

Passarelli, L., Brodsky, E.E., 2012. The correlation between run-up and repose times of volcanic eruptions. Geophys. J. Int. 188, 1025-1045

Power, J.A., Stihler, S.D., White, R.A., Moran, S.C., 2004. Observations of deep longperiod (DLP) seismic events beneath Aleutian arc volcanoes, 1989-2002. J. Volcanol. Geotherm. Res. 138, 243-266.

Power, J.A., Stihler, S.D., Chouet, B.A., Haney, M.M., Ketner, D.M., 2013. Seismic observations of Redoubt Volcano, Alaska - 1989-2010 and a conceptual model of the Redoubt magmatic system. J. Volcanol. Geotherm. Res. 259, 31-44.

Putirka, K.D., 2017. Down the crater: where magmas are stored and why they erupt. Elements 13, 11-16.

Putirka, K.D., Perfit, M., Ryerson, F.J., Jackson, M.G., 2007. Ambient and excess mantle temperatures, olivine thermometry, and active vs. passive upwelling. Chem. Geol. 241, 177-206.

Rae, A.S.P., Edmonds, M., Maclennan, J., Morgan, D., Houghton, B., Hartley, M.E., Sides, I., 2016. Time scales of magma transport and mixing at Killauea Volcano, Hawai'i. Geology 44, 463-466. 
Rasmussen, D.J., Kyle, P.R., Wallace, P.J., Sims, K.W.W., Gaetani, G.A., Phillips, E.H., 2017. Understanding degassing and transport of $\mathrm{CO}_{2}$-rich alkalic magmas at Ross Island, Antarctica using olivine-hosted melt inclusions. J. Petrol. 58, 841-861.

Roman, D.C., Gardine, M.D., 2013. Seismological evidence for long-term and rapidly accelerating magma pressurization preceding the 2009 eruption of Redoubt Volcano, Alaska. Earth Planet. Sci. Lett. 371, 226-234.

Savage, M.K., Wessel, A., Teanby, N.A., Hurst, A.W., 2010. Automatic measurement of shear wave splitting and applications to time varying anisotropy at Mount Ruapehu volcano, New Zealand. J. Geophys. Res., Solid Earth 115.

Shea, T., Costa, F., Krimer, D., Hammer, J.E., 2015a. Accuracy of timescales retrieved from diffusion modeling in olivine: a 3D perspective. Am. Mineral. 100, 2026-2042.

Shea, T., Lynn, K.J., Garcia, M.O., 2015b. Cracking the olivine zoning code: distinguishing between crystal growth and diffusion. Geology 43, 935-938.

Sparks, R.S.J., 2003. Forecasting volcanic eruptions. Earth Planet. Sci. Lett. 210, 1-15.

Sparks, R.S.J., Sigurdsson, H., Wilson, L., 1977. Magma mixing: a mechanism for triggering acid explosive eruptions. Nature 267, 315-318.

Spilliaert, N., Allard, P., Métrich, N., Sobolev, A.V., 2006. Melt inclusion record of the conditions of ascent, degassing, and extrusion of volatile-rich alkali basalt during the powerful 2002 flank eruption of Mount Etna (Italy). J. Geophys. Res., Solid Earth 111, B04203. https://doi.org/10.1029/2005JB003934.
Stelling, P., Beget, J., Nye, C., Gardner, J., Devine, J., George, R., 2002. Geology and petrology of ejecta from the 1999 eruption of Shishaldin Volcano, Alaska. Bull. Volcanol. 64, 548-561.

Streck, M.J., 2008. Mineral textures and zoning as evidence for open system processes. Rev. Mineral. Geochem. 69, 595-622.

Thompson, G., McNutt, S., Tytgat, G., 2002. Three distinct regimes of volcanic tremor associated with the eruption of Shishaldin Volcano, Alaska 1999. Bull. Volcanol. 64, 535-547.

Toplis, M.J., 2005. The thermodynamics of iron and magnesium partitioning between olivine and liquid: criteria for assessing and predicting equilibrium in natura and experimental systems. Contrib. Mineral. Petrol. 149, 22-39.

White, R.A., 1996. Precursory deep long-period earthquakes at Mount Pinatubo: spatio-temporal link to a basalt trigger. In: Fire and Mud: Eruptions and Lahars of Mount Pinatubo, Philippines, pp. 307-328.

Zimmer, M.M., Plank, T., Hauri, E.H., Yogodzinski, G.M., Stelling, P., Larsen, J., Singer B., Jicha, B., Mandeville, C., Nye, C.J., 2010. The role of water in generating the calc-alkaline trend: new volatile data for Aleutian magmas and a new tholeiitic index. J. Petrol. 51, 2411-2444. 